UNIVERSIDADE DE SÃo PAULO

Hospital de REAbiLITAÇÃo DE ANOMALIAs CRANIOFACIAIS

\title{
Avaliação da Estética Facial de Pacientes com Fissura TrANSFORAME INCISIVO BILATERAL, SUBMETIDOS AO Protocolo de Cirurgias do HRAC-USP
}

\author{
Rita de Cássia Moura Carvalho Lauris
}

\begin{abstract}
Dissertação apresentada ao Hospital de Reabilitação de Anomalias Craniofaciais da Universidade de São Paulo, para obtenção do título de MESTRE em Ciências da Reabilitação. Área de concentração: Fissuras Orofaciais.
\end{abstract}


UNIVERSIDADE DE SÃO PAULO

HospitAl DE REABILITAÇÃO DE ANOMALIAS CRANIOFACIAIS

\title{
Avaliação da Estética Facial de Pacientes com Fissura TrANSFORAME INCISIVO BILATERAL, SUBMETIDOS AO Protocolo de Cirurgias do HRAC-USP
}

Rita de Cássia Moura Carvalho Lauris ORIENTADOR: Prof. DR. LEOPOLDINO CAPELOZZA FILHO

\author{
Dissertação apresentada ao Hospital de \\ Reabilitação de Anomalias Craniofaciais da \\ Universidade de São Paulo, para obtenção do \\ título de MESTRE em Ciências da Reabilitação. \\ Área de concentração: Fissuras Orofaciais.
}




\section{UNIVERSIDAde DE SÃo PAULO \\ HospitAl DE REABILITAÇÃo DE ANOMALIAS CRANIOFACIAIS}

Rua Sílvio Marchione, 3-20

Caixa Postal 1501

17012-900

Bauru - SP - Brasil

Fone: (14) 3235-8000

Prof. Dr Adolpho José Melfi - Reitor da USP

Prof. Dr. José Alberto de Souza Freitas - Superintendente do HRAC-USP

Autorizo, exclusivamente, para fins acadêmicos e científicos, a reprodução total ou parcial deste trabalho.

Rita de Cássia Moura Carvalho Lauris

Bauru, de de

Lauris, Rita de Cássia Moura Carvalho

L375a Avaliação da Estética Facial de Pacientes com Fissura Transforame Incisivo Bilateral, Submetidos ao Protocolo de Cirurgias do HRAC-USP / Rita de Cássia Moura Carvalho Lauris. Bauru, 2005.

52p.:il.;29,7cm

Dissertação (Mestrado - Área de concentração: Fissuras Orofaciais) - HRAC-USP.

Cópia revisada em

Orientador: Leopoldino Capelozza Filho

Descritores: 1. análise facial 2. fissura transforame incisivo bilateral 3 . estética 


\section{FOLHA DE APROVAÇÃo}

Dissertação apresentada e defendida por Rita de Cássia Moura Carvalho Lauris e aprovada pela Comissão Julgadora em

Prof(a). Dr(a).

Instituiçao

Prof(a). Dr(a).

Instituiçao

$\operatorname{Prof}(a) . \operatorname{Dr}(a)$.

Instituiçao

Prof. Dr. Leopoldino Capelozza Filho HRAC/USP (Orientador)

Prof. Dr.

Presidente da Comissão de Pós-Graduação do HRAC/USP

Data de depósito da dissertação junto à SPG 


\section{Rita de Cássia Moura CaRvalho LaURis}

13 de abril de 1966

Goiânia/GO

Filiação

$1983-1987$

$1988-1989$

1989-1991

1993

1995

1998

$2002-2005$

Associações
Nascimento

Elon Carvalho

Aurora Luiza de Moura Carvalho

Curso de Odontologia - Faculdades Integradas de Uberaba, FIUBE

Residência Odontológica em Ortodontia Preventiva e Interceptiva - Hospital de Reabilitação de Anomalias Craniofaciais da Universidade de São Paulo, HRAC-USP

Especialização em Ortodontia - Sociedade de Promoção Social do Fissurado Lábio Palatal, PROFIS

Professora do Curso de Ortodontia Preventiva e Interceptiva da PROFIS-FUNCRAF

Professora do Curso de Typodont da PROFISFUNCRAF

Ortodontista do HRAC-USP

Mestrado em Ciências da Reabilitação, área de concentração: Fisuras Orofaciais - HRAC-USP

ABO -Associação Brasileira de Odontologia APEO - Associação Paulista de Ortodontia GREO - Grupo de Residentes e Especialistas da PROFIS-FUNCRAF 
Dedicatória 
Dedico este trabalho

Aos meus pais, Elon e Aurora, pelos sacrifícios, zelo e amor com que nos educaram, grandes incentivadores dos nossos estudos e meus exemplos de determinação e caráter.

Ao meu esposo José Roberto e meus filhos Natália e Gabriel, pelas privacões motivadas pelo trabalho e vocês, com extrema compreensão deram-me o apoio e suporte necessários, épara vocês que ofereço os meus dias, sem vocês minha vida seria em preto e branco

querido, a você meu eterno amor e agradecimento por tantos conbecimentos trocados, pela primorosa análise estatística e revisão desse trabalho, pela dedicação a mim e aos nossos filhos, é uma dádiva tê-lo como par. 
Agradecimentos 
A Deus,

pela sua bondade infinita em

cercar minha vida de pessoas tão especiais. 
Ao Prof. Leopoldino Capelozza Filho, meu mestre e orientador minha gratidão, pelo primeiro convite para estagiar no Centrinho, do qual nunca mais me afastei, suas lições nesses anos nunca serão esquecidas, espero poder retribuir sua confiança depositada em mim. 
Agradecimento especial

Professor Dr. José Alberto de Souza Freitas

Obrigado!

O sonho tornou-se realidade. A missão de reabilitar está sendo cumprida.

No começo, tudo novo, desconhecido.

No presente, conhecimento reconhecido.

Evolução que permite avaliação.

Não mais da radiografia ou dos modelos, mas da face!

Retrato das possibilidades e limitações.

Possibilidades que confortam,

Limitações que estimulam. Aprender, ensinar, fazer e corrigit. Obrigado por tornar isso possível.

Pesquisador: Rita de Cássia Moura Carvalho Lauris Orientador: Prof. Dr. Leopoldino Capelozza Filho 
Ao Prof. Omar, pelos ensinamentos, incentivo, confiança e parceria ao longo desses anos, conte sempre comigo.

A Dra. Arlete, Dra. Terumi, Dra. Sílvia, Dra Patrícia, Dr. Aiello e Dra. Araci, trabalhar com vocês é uma honra e felicidade, obrigada pela amizade, carinho, paciência, além do apoio durante todo o Curso.

As auxiliares do Setor de Ortodontia, Suzana, Solange, Leila, Denise, Rosângela e Sônia, pelo suporte, bom bumor e disposição, tornando o nosso trabalho tão agradável.

A todos os residentes do Setor de Ortodontia, representados pela turma atual de Corretiva e Preventiva, Helena, Ana Paula, Fernando, Juliano, Larissa, Thiago, Ghisa, Tatiana, Guilherme G., Marcelo, Heloísa, Anderson, Juliana, Fernanda, Guilherme P., William, Rodrigo e Gustavo, pelos conbecimentos trocados, amizade, apoio e compreensão,em especial a Larissa pelo auxilio na metodologia.

Aos alunos e funcionários do Curso de Ortodontia Preventiva e Interceptiva da PROFIS-FUNCRAF, pelo apoio, amizade e agradável convívio.

A Profa. Ana Grigolli e equipe da UEP e arquivo de slides Jane, Ana Regina, Denise, Rose, Edson e Polyana, pela disposição, prontidão e competência.

Ao Setor de Pós-Graduação, Dra. Inge, Andréia, Rogério, Zezé, Rosibel e Saulo, pela dedicaşão, suporte, apoio e tolerância.

Às equipes da Central de Agendamento e Arquivo de Prontuátios representadas pela Vilminha, Inês, Elisa e Clarisse, pelo apoio na coleta de amostra.

Ao Setor Odontológico do Centrinho, Representado pelo Dr. Laerte, pelo incentivo e suporte na metodologia do trabalho, além da amizade. 
Aos profissionais colegas do Setor Odontológico, todos vocês são especiais, obrigada pela amizade.

Aos avaliadores do trabalho na qualificação, Dr. João Henrique, Dr. Adilson e Dr. Barbieri, pelas valiosas consideracõoes e sugestões.

Às equipes do Setor de Manutenção e Radiologia Médica, pelo suporte na metodologia do trabalho e por ceder espaço para o estúdio fotográfico.

À equipe do CPD, representada pela Márcia, pelo apoio com a amostra e pela amizade.

À Lucília e ao Alexandre, pela atenção e suporte na metodologia do trabalho.

Ao setor de recepção e distribuição de prontuátios, pela prontidão.

À equipe da Comunicação, representada pela Marisa, Ellen, Camila, Elaine e Márcio, pelo apoio, disposição e amiz̧ade.

Ao Marcos e Marcelo da Hobby Photo, pelo suporte com as fotografias e montagem do estúdio.

A Sílvia Reis, pela inspiração da metodologia e doação da estativa.

Aos grupos de examinadores da amostra, Dr. Garla, Dra. Telma, Dr. Eudes, Dr. Carlos Eduardo e Dr. Marcos Lupércio, Dra. Arlete, Dra. Terumi, Dra. Sílvia, Dra. Patrícia e Dr. Omar, Dra. Ana Cláudia Conti, Dra. Karina Lima, Dra. Karina Valle, Dra. Leniana, Dr. Rodrigo, Dr. Alberto Okada, Dr. Aluísio, Dr. Leandro P., Dr. Leandro Rodrigues, Dra Maria Oyagawa, Dr. Sílvio Reginato Jr., Dr. Aquiles Sormani, Dra. Elaine Mesquita, Dr. Geraldo Mesquita,

Dra. Gislaine Lauris, pela gentileza de colaborar com o estudo, suas opiniōes foram de extrema importância, agradeço especialmente à Ana Cláudia que reuniu o Grupo de Ortodontistas. 
Ao Dr. Richieri, representando os professores da Pós-Graduação, pela consideração e disposição em transmitir conhecimentos.

\author{
A Gisele Dalben, \\ pela versão do resumo. \\ À Sueli, \\ pela atenção e ajuda na revisão das tabelas. \\ A Fernanda, secretária da Ortodontia Preventiva \\ pela atenção.
}

Ao Fabrício, Ariana e Rafaela, pela disposição e arte.

Ao Marcos e Ana Amélia, pela impressão e gentileza.

Aos amigos e colegas de Curso, Eduardo, Fernando, Gustavo, Homero, Marcelo, Rodrigo, Rosa, Gisele, Flávio, Aiello, Nárima e Araci, pela cumplicidade e amizade a toda hora, contem comigo para sempre.

Às companheiras de clínica, Karla, Sueli, Ivanil, Mayra, Nancy e Priscila, a convivência com vocês enriquece o dia-a-dia, obrigada pela amizade.

Aos pacientes e pais, vocês são a rąão das nossas pesquisas, obrigada pela prontidão em participar do estudo.

Ao Hospital de Reabilitação de Anomalias Craniofaciais, querido Centrinho, representado pelo Dr. Gastão, e todos os setores e funcionários, obrigada por terem me recebido. 
Aos meus irmãos Fabiana, Luiz Cláudio, Luiz Eduardo, minha cunhada Débora, meus sobrinhos Guilherme, Vinícius, Carolina e Juliana, pela cumplicidade apesar da distância, agradeço a Deus pela existência de vocês, obrigada pelo amparo.

\author{
A toda Família Pereira Lauris, \\ representados pela Márcia, Omar, Paulo, Gislaine, Victória, Camila, \\ obrigada por me acolher como um dos seus e nos dedicar tanto carinho, \\ é muito confortável contar com pessoas preciosas como vocês.
}

Aos meus queridos amigos de Bauru, os quais seria impossível citá-los todos, pelo companheirismo, pela amizade marcante, vocês são uma extensão da minha familia

Aos meus tios Alda e Antônio, vocês representaram minha casa durante parte da faculdade, nunca os esquecerei, obrigada.

A todos os meus professores, do maternal até a Pós-Graduação, representados pela minha tia e madrinha Madalena,

sua influência não tem limites, pelos seus ensinamentos que me ajudaram a melhorar como pessoa.

À todos que colaboraram indiretamente para a conclusão desse trabalho

$E$ que por ventura não foram relacionados Muito obrigada! 
Sumário 


\section{SUMÁRIO}

LISTA DE FIGURAS ……………………………………........................ xvi

LISTA DE TABELAS …………………………………............................ xviii

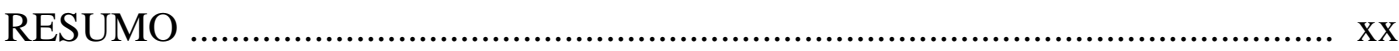

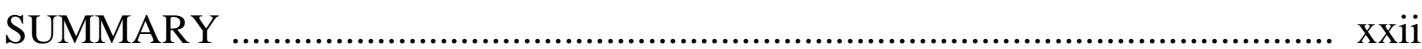

INTRODUÇÃO E REVISÃO DE LITERATURA …………………………..... 01

1.1. A fissura e o protocolo de cirurgias do HRAC-USP …………………....... 02

1.2. A estética facial e sua avaliação ............................................................... 06

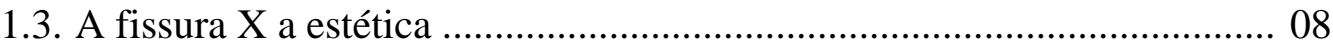

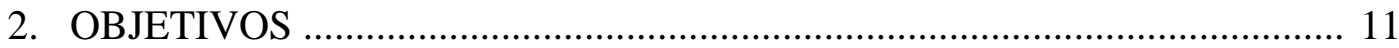

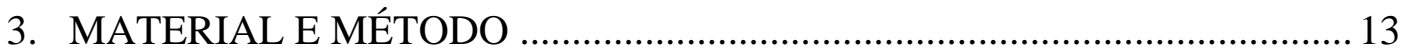

3.1. Amostra de pacientes ................................................................................ 14

3.2. Método de obtenção das fotografias ....................................................... 14

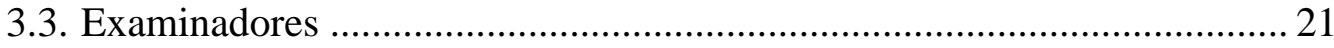

3.4. Análise estatística ……………………………………………………….... 21

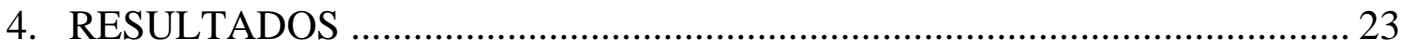

4.1. Concordância intra e inter-examinadores .................................................. 28

4.2. Comparação dos escores atribuídos por categoria de examinador ..............31

4.3. Estruturas responsáveis pela classificação esteticamente desagradável ....36

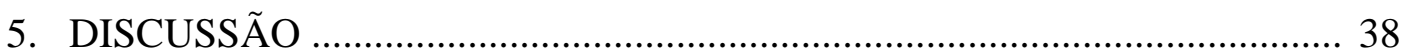

5.1. Considerações a respeito da metodologia ................................................. 39

5.2. Considerações a respeito dos resultados ................................................... 40

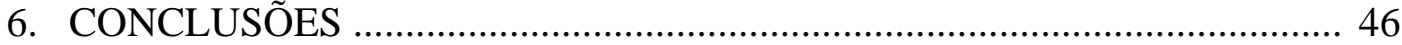

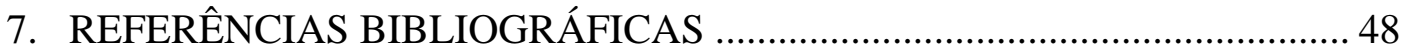
ANEXOS 
Lista de Figuras 


\section{LISTA DE FIGURAS}

Figura 1 - Paciente com fissura transforame incisivo bilateral, aos 7 anos de idade, operado de lábio, palato e columela nasal

Figura 2 - Protocolo de intenções cirúrgicas defendido pelo HRAC-USP para reabilitação das fissuras.

Figura 3 - Especificações da máquina fotográfica 15

Figura 4 - Câmera digital Coolpix 995 Nikon ................................................... 16

Figura 5 - $\quad$ Especificações da caixa de luz ........................................................... 16

Figura 6 - $\quad$ Especificações do flash com sombrinha ............................................... 16

Figura 7 - Especificações para obtenção das fotografias

Figura 8 - a) Cefalostato, caixa de luz, espelho e linha vertical verdadeira; b) detalhe do prumo preso à ponta da linha vertical verdadeira

Figura 9 - Posicionamento da linha vertical verdadeira à frente do paciente

Figura 10 - a)Tomada fotográfica com o paciente posicionado no cefalostato e a caixa de luz acesa; b) Posicionamento adequado do paciente frente ao espelho inclinado

Figura 11 - Fotografia do perfil direito em tamanho real $(10 \times 15 \mathrm{~cm})$

Figura 12 - Fotografia dos perfil esquerdo em tamanho real $(10 \times 15 \mathrm{~cm})$ 20

Figura 13 - Paciente que obteve escore mais alto $(6,2)$

Figura 14 - Paciente que obteve escore intermediário $(4,4)$

Figura 15 - Paciente que obteve escore mais baixo $(2,8)$

Figura 16 - Valores da mediana, $1^{0}$ quartil, $3^{0}$ quartil, mínimo e máximo por categoria

Figura 17 - Distribuição das classificações por categoria de examinador 35

Figura 18 - Estruturas do perfil facial reconhecidas pelos examinadores como responsáveis pela classificação em esteticamente desagradável ..... 
Iista de Tabelas 


\section{LISTA DE TABELAS}

Tabela 1 - Média, mediana, $1^{\circ}$ quartil, $3^{\circ}$ quartil, mínimo e máximo dos escores atribuídos pelos 25 examinadores na $1^{\text {a }}$ avaliação

Tabela 2 - Média, mediana, $1^{\circ}$ quartil, $3^{\circ}$ quartil, mínimo e máximo dos escores atribuídos pelos 25 examinadores na $2^{\mathrm{a}}$ avaliação

Tabela 3 - Coeficiente de concordância de Kendall (W) entre os examinadores de cada categoria na $1^{\mathrm{a}}$ avaliação

Tabela 4 - Coeficiente de concordância de Kendall (W) entre os examinadores de cada categoria na $2^{\mathrm{a}}$ avaliação

Tabela 5 - Coeficiente de correlação de Spearman $\left(r_{s}\right)$ entre a $1^{\mathrm{a}}$ e $2^{\mathrm{a}}$ avaliação de cada um dos 25 examinadores

Tabela 6 - Coeficiente de Concordância de Kendall (W) entre as 5 categorias

Tabela 7 - Mediana das avaliações por categoria de examinador

Tabela 8 - Média, mediana, $1^{\circ}$ quartil, $3^{\circ}$ quartil, mínimo e máximo dos escores atribuídos por categoria

Tabela 9 - Distribuição das classificações atribuídas pelos 25 examinadores

Tabela 10 - Porcentagem de pacientes classificados como esteticamente Desagradável, por categoria de examinador

Tabela 11 - Estruturas do perfil facial reconhecidas pelos examinadores como responsáveis pela classificação em esteticamente desagradável. 
Resumo 


\section{RESUMO}

LAURIS, RCMC. Avaliação da estética facial de pacientes com fissura transforame incisivo bilateral, submetidos ao protocolo de cirurgias do HRAC-USP [dissertação]. Bauru: Hospital de Reabilitação de Anomalias Craniofaciais, Universidade de São Paulo; 2005.

Objetivo: avaliar por meio de fotografias de perfil e um questionário específico, a estética facial de indivíduos com fissura transforame incisivo bilateral (FTB), operados segundo o protocolo do HRAC-USP.

Modelo: Estudo transversal, com análise das fotografias, atribuindo escores aos pacientes e comparando-os estatisticamente.

Local de Execução: HRAC-USP.

Participantes: Amostra: 30 pacientes, 24 do gênero masculino e 6 do gênero feminino, com idades entre 5 anos e 8 meses a 10 anos e 4 meses, leucodermas, com FTB . Examinadores: 5 Ortodontistas do HRAC-USP (OHRAC), 5 Ortodontistas não relacionados à área de fissura (ONF), 5 Cirurgiões Plásticos do HRAC-USP (CPHRAC), 5 Cirurgiões Plásticos não relacionados à área de fissura (CPNF), 5 leigos (L) com formação superior.

Variáveis: classificação da agradabilidade facial, em escala de 1 a 9 , estruturas reconhecidas como responsáveis pela pior classificação.

Resultados: O grupo OHRAC atribuiu mediana de 7 (aparência esteticamente agradável), o grupo CPHRAC atribuiu 5 (esteticamente aceitável). O grupo L atribuiu 4 (esteticamente aceitável). Os grupos ONF e CPNF, designaram 3 (esteticamente desagradável). Existiu diferença significante entre todas as categorias, exceto para os ONF e CPNF. Foram associadas à classificação esteticamente desagradável o nariz, o terço médio da face e o lábio superior.

Conclusões: A estética facial da amostra foi classificada em agradável (grupo OHRAC), aceitável (grupos CPHRAC e L) e desagradável (grupos ONF e CPNF). Houve diferença significante entre os grupos, exceto para os ONF e CPNF. As estruturas associadas aos piores escores foram o nariz, o terço médio da face e o lábio superior.

Descritores: análise facial, fissura transforame incisivo bilateral, estética 
Summayy 


\section{SUMMARY}

LAURIS, RCMC. Evaluation of the facial esthetics of patients with complete bilateral cleft lip and palate submitted to the surgical protocol of HRAC-USP [dissertação]. Bauru: Hospital de Reabilitação de Anomalias Craniofaciais, Universidade de São Paulo; 2005.

Objective: to evaluate, by means of photographs of profile and a specific questionnaire, the facial esthetics of individuals with complete bilateral cleft lip and palate (CBCLP) operated according to the protocol of HRAC-USP.

Design: cross-sectional study with analysis of the photographs, by assignment of scores to the patients and statistical comparison.

Setting: HRAC-USP.

Participants: sample: 30 white patients with CBCLP, being 24 males and 6 females, aged 5 years 8 months to 10 years 4 months. Examines: 5 orthodontists of HRAC-USP (OHRAC), 5 orthodontists not treating patients with clefts (ONC), 5 plastic surgeons of HRAC-USP (PSHRAC), 5 plastic surgeons not treating patients with clefts (PSNC), and 5 lay graduated examiners (L).

Variables: classification of facial pleasantness in a scale from 1 to 9, structures recognized as responsible for the worst classification.

Results: the OHRAC group assigned a median of 7 (esthetically pleasant appearance) and the PSHRAC assigned 5 (esthetically acceptable). Group L assigned 4 (esthetically acceptable). Groups ONC and PSNC assigned 3 (esthetically unpleasant). There was a significant difference between all categories, except for ONC and PSNC. The structures associated to the esthetically unpleasant classification were the nose, middle third of the face and upper lip.

Conclusions: the facial esthetics of the sample was classified as pleasant (OHRAC group), acceptable (PSHRAC and L groups) and unpleasant (ONC and PSNC groups). There was a significant difference between groups, except for the ONC and PSNC. The structures associated to the worst scores were the nose, middle third of the face and upper lip.

Key Words: facial analysis, complete bilateral cleft lip and palate, esthetics 
Introducão e Revisão de Literatura 


\section{INTRODUÇ̃̃O E REVISÃO DE LITERATURA.}

\subsection{A fissura e o protocolo de cirurgias do Hospital de Reabilitação de Anomalias Craniofaciais da Universidade de São Paulo ( HRAC-USP).}

Dentre os defeitos congênitos que acometem a face humana, as fissuras labiopalatinas representam os mais comuns, sendo exteriorizadas clinicamente pela descontinuidade de algumas das estruturas que compõem a face média, tais como o lábio superior, o rebordo alveolar e o palato. Surgem na vida pré-natal, durante a formação da face e sua alta prevalência é explicada pela complexidade do desenvolvimento embrionário humano (Capelozza Filho e Silva Filho 1992). No Sudeste do Brasil, este defeito acomete entre 1:1000 e 1:2000 indivíduos nascidos vivos, segundo dados do Estudio Colaborativo Latino Americano de Malformaciones Congênitas (ECLAMC) (Castilla et al 1995).

Segundo a classificação de Spina (1972), modificada por Silva Filho et al (1992), tendo como referência anatômica o forame incisivo, as fissuras podem ser divididas em pré-forame unilateral, bilateral e mediana; transforame unilateral, bilateral e mediana; pós-forame incompleta e completa; e fissuras raras da face.

A fissura transforame incisivo bilateral, ou seja, completa de lábio e palato, constitui a manifestação mais severa dentre as malformações congênitas labiopalatinas, e ocorre em 16,54\% dos casos de fissura lábio-palatal (Capelozza Filho e Silva Filho 1992).

A presença da fissura impõe à face características intrínsecas de crescimento, que difere do normal, criando uma morfologia craniofacial típica (Silva Filho et al 1998). As cirurgias primárias de lábio (queiloplastia) e palato (palatoplastia), quando realizadas na infância, imprimem mudanças na configuração facial, ao longo do crescimento (Capelozza Filho e Silva Filho 1992, 2002; Semb 1991).

Ao nascer, o paciente com fissura transforame incisivo bilateral geralmente exibe uma maxila com moderada deficiência tecidual, dividida em 3 segmentos 
distintos, dois laterais simétricos, os processos palatinos, e um central de tamanho variável e fixado na extremidade anterior do septo nasal, a pré-maxila, que mostra grande mobilidade. Em função disto, a maxila mostra-se maior em todas as dimensões laterais e ântero-posteriores. A projeção da pré-maxila, presente desde a décima semana de vida intra-uterina, é acentuada e provocada pela excessiva aposição óssea na sua junção com o vômer. Isso dá ao perfil facial uma convexidade exagerada, a qual diminui sensivelmente após a cirurgia de lábio e progressivamente após ela, mantendo, porém, até a puberdade as características do perfil. A partir daí, com o crescimento, há uma tendência muito bem definida, de equiparação da convexidade facial nos pacientes com esse tipo de fissura com a considerada normal. Obedecendo a uma característica filogenética do homem, e em um grau de intensidade dependendo do genótipo de cada indivíduo, o paciente com fissura transforame incisivo bilateral exibe um crescimento mais acentuado da mandíbula nesta fase, passando a exibir então, uma convexidade facial igual ou menor que o normal. As dimensões transversais da maxila também se alteram após as cirurgias, principalmente após a cirurgia do palato. Nota-se uma constrição acentuada na região anterior, mais moderada na mediana e uma manutenção ou aumento da distância intertuberosidade. Os dentes da pré-maxila (incisivos) exibem normalmente uma inclinação vestibular diminuída, assim como os inferiores, e uma sobressaliência e sobremordida aumentadas. A mandíbula é retroposta durante toda a fase evolutiva, além de exibir dimensão menor ou igual ao normal. Devido ao aumento do ângulo goníaco com o crescimento, a face torna-se retrognática e longa, principalmente no terço inferior (Capelozza Filho e Silva Filho 1992).

O perfil tegumentar, assim como as estruturas ósseas e dentárias, exibe características próprias de crescimento, embora haja poucos trabalhos descrevendo isso. Ao nascer, o pró-lábio está protruído, a columela está ausente e a protrusão nasal é mínima. Após a reparação cirúrgica, o comprimento do lábio superior é geralmente maior, e ele é proeminente assim como o lábio inferior. A convexidade do perfil mole é acentuada, apesar da pouca projeção nasal. Por volta dos 6 anos, as relações labiais estão próximas do normal, com uma protrusão do lábio inferior geralmente maior. As espessuras dos lábios superior e inferior, e do pogônio não diferem do normal. Até a pré-puberdade o crescimento é favorável, diminuindo a retrusão mandibular, o que contribui esteticamente (Capelozza Filho e Silva Filho 1992). 
A figura 1 mostra um paciente com fissura transforame incisivo bilateral, aos 7 anos de idade, operado de lábio, palato e após a cirurgia de alongamento da columela nasal.
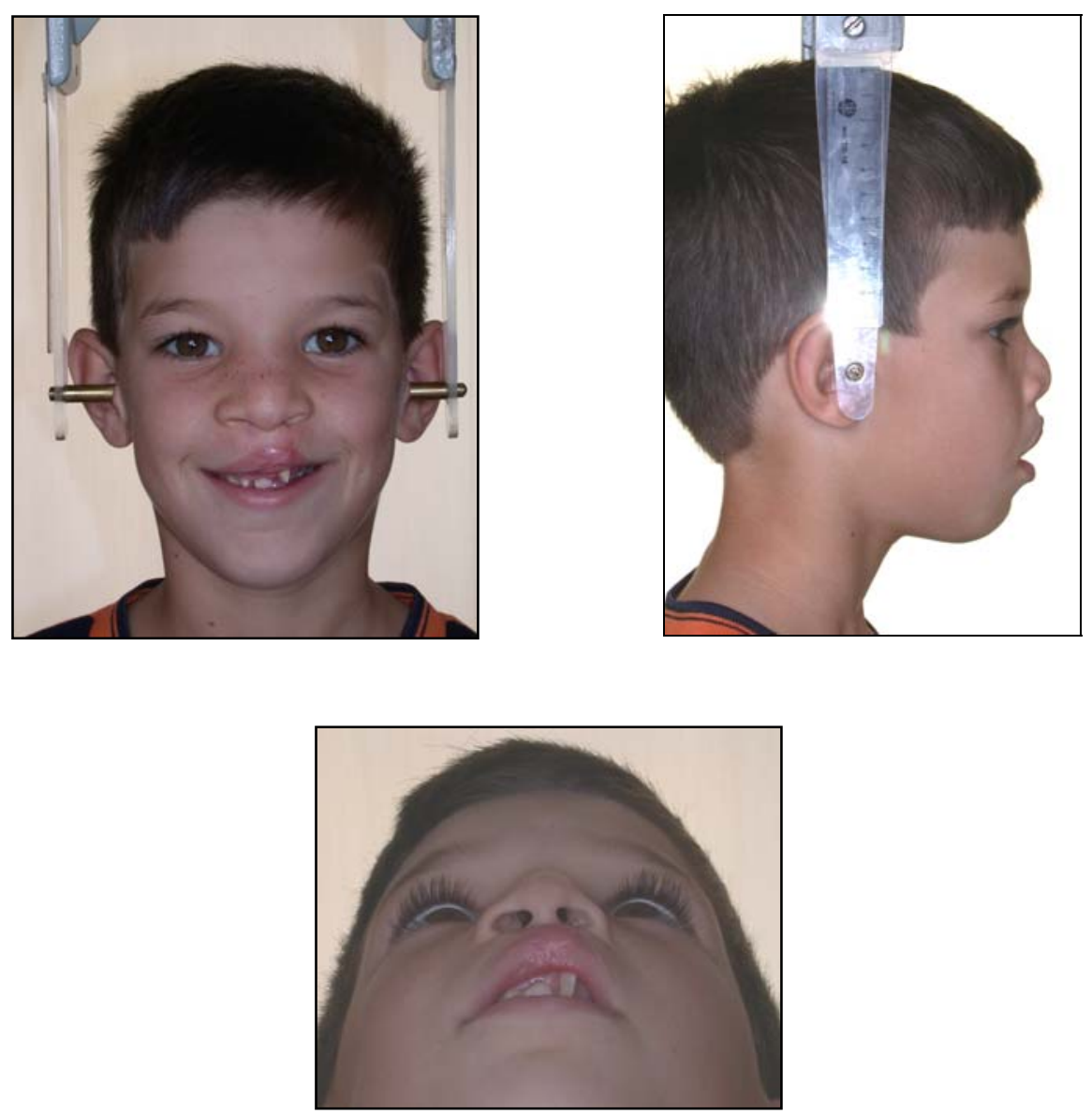

Figura 1 - Paciente com fissura transforame incisivo bilateral, aos 7 anos de idade, operado de lábio, palato e columela nasal

O protocolo de cirurgias do Hospital de Reabilitação de Anomalias Craniofaciais da Universidade de São Paulo (HRAC-USP) para a fissura transforame incisivo bilateral envolve as seguintes etapas: a queiloplastia, que pode ser realizada aos 3 meses de idade em tempo único, ou seja, os dois lados simultaneamente, ou em dois tempos cirúrgicos aos 3 e aos 6 meses; a palatoplastia aos 12 meses; a queiloplastia definitiva juntamente com a columela nasal aos 6 anos; o enxerto ósseo alveolar secundário entre 9 e 12 anos e a cirurgia ortognática na maturidade esquelética. A figura 2 expressa o protocolo de cirurgias do HRAC-USP, com as diferenças entre as indicações conforme o tipo de fissura (Capelozza Filho e Silva Filho 2002). 


\begin{tabular}{|c|c|c|c|c|c|}
\hline Cirurgia & $\begin{array}{l}\text { Pré-forame } \\
\text { unilateral }\end{array}$ & $\begin{array}{l}\text { Pré-forame } \\
\text { Bilateral }\end{array}$ & $\begin{array}{l}\text { Transforame } \\
\text { Unilateral }\end{array}$ & $\begin{array}{l}\text { Transforame } \\
\text { Bilateral }\end{array}$ & Pós-forame \\
\hline \multirow{2}{*}{ Queiloplastia } & \multirow{2}{*}{3 meses } & $\begin{array}{c}3 \text { meses } \\
\text { (tempo único) }\end{array}$ & 3 meses & $\begin{array}{c}3 \text { meses } \\
\text { (tempo único) }\end{array}$ & - \\
\hline & & $\begin{array}{c}3 \text { meses e } 6 \text { meses } \\
\text { (2 tempos cirúrgicos) }\end{array}$ & & $\begin{array}{l}3 \text { meses e } 6 \text { meses } \\
\text { (2 tempos cirúrgicos) }\end{array}$ & \\
\hline Palatoplastia & - & - & 12 meses & 12 meses & 12 meses \\
\hline $\begin{array}{c}\text { Queiloplastia } \\
\text { definitiva + } \\
\text { columela }\end{array}$ & - & 6 anos & - & 6 anos & - \\
\hline $\begin{array}{l}\text { Enxerto ósseo } \\
\text { secundário }\end{array}$ & $\begin{array}{c}9-12 \\
\text { anos }\end{array}$ & $\begin{array}{l}9-12 \\
\text { anos }\end{array}$ & $\begin{array}{c}9-12 \\
\text { anos }\end{array}$ & $\begin{array}{c}9-12 \\
\text { anos }\end{array}$ & - \\
\hline $\begin{array}{l}\text { Cirurgia } \\
\text { ortognática }\end{array}$ & - & - & $\begin{array}{l}\text { Maturidade } \\
\text { esquelética }\end{array}$ & $\begin{array}{l}\text { Maturidade } \\
\text { esquelética }\end{array}$ & - \\
\hline
\end{tabular}

Figura 2 - Protocolo de intenções cirúrgicas defendido pelo HRAC-USP para reabilitação das fissuras

Fonte: Capelozza Filho L, Silva Filho OG. Abordagem interdisciplinar no tratamento das fissuras labiopalatinas. In: Mêlega JC, editor. Cirurgia Plástica fundamentos e arte: cirurgia reparadora da cabeça e pescoço. Rio de Janeiro: Medsi; 2002. p.59-88.

Toda equipe interdisciplinar que trabalha na reabilitação das fissuras labiopalatinas enfrenta arduamente implicações psicológicas, estéticas e funcionais inerentes a esse tipo de malformação. O tratamento é longo e altamente especializado, envolvendo diferentes especialidades para a reabilitação completa dos pacientes com essa malformação.

Ozawa (2001) realizou uma avaliação dos efeitos da queiloplastia e palatoplastia primárias sobre o crescimento dos arcos dentários de crianças com fissura transforame incisivo unilateral entre 5 e 6 anos de idade, comparando o protocolo do HRAC-USP com o de Oslo, Noruega. Na comparação dos resultados intercentros observou-se superioridade nos resultados médios de Oslo sobre os de Bauru. Além da amplitude da fissura, a habilidade do cirurgião pareceu interferir também na relação interarcos final. Cirugiões experientes que operaram seguindo os protocolos de rotina do HRAC-USP apresentaram resultados tão bons quanto o protocolo de Oslo. Os resultados sugerem 
que, mais do que a técnica cirúrgica em si, a habilidade e experiência do profissional são fatores decisivos nos resultados interarcos.

Shaw et al (1992), realizaram uma série de estudos comparando 6 centros internacionais de reabilitação de pacientes com fissura unilateral de lábio e palato e concluíram que resultados aceitáveis podem ser conseguidos por diferentes programas de reabilitação. Entretanto a padronização, centralização e participação interdisciplinar de um grande número de profissionais, além de um protocolo menos complexo foram relacionados aos melhores resultados.

\subsection{A estética facial e sua avaliação.}

O senso estético está relacionado a vários aspectos, tais como condições sócioeconômicas, fatores geográficos e conceitos culturais; entretanto, via de regra é na face que a estética é analisada inicialmente e é pela face que um indivíduo se apresenta à sociedade e é reconhecido por seus semelhantes. É inegável, portanto que a estética assume grande importância na construção da auto-estima e na inter-relação pessoal (Farkas e Kolar 1987).

A sociedade caracteriza-se pelo estabelecimento de padrões de preferência estética e a face é um recurso chave na determinação da atratividade física. O estudo da estética facial é de grande relevância para os Ortodontistas. Mais que isso, é um assunto que interessa a população em geral ao redor do mundo (Peck e Peck 1970).

Já foi demonstrado que a beleza facial depende de um estado de equilíbrio e harmonia das proporções faciais estabelecidas pelas estruturas que compõem a face, dentes, esqueleto craniofacial e tecidos moles (Okuyama e Martins, 1997).

A avaliação da estética facial exibe uma grande subjetividade, pois representa pontos de vista individuais, além de variar de acordo com fatores étnicos, etários e padrões culturais correspondentes a uma determinada população em um determinado tempo, contudo há uma tendência na sociedade como um todo, de ter conceitos semelhantes sobre estética agradável e desagradável. (Wuerpel 1931, Morris 1994)

Autores como Howells e Shaw (1985) testaram a validade e a reprodutibilidade de fotografias como método de avaliação da estética facial e dental com fins epidemiológicos. Concluíram ser um método viável, apesar dos resultados apresentarem 
diferença entre a avaliação ao vivo e a fotográfica, com notas mais altas para os indivíduos ao vivo. Outro fator observado foi a necessidade de um grupo maior de examinadores para aumentar a confiabilidade do estudo, uma vez que o mesmo contava com apenas dois examinadores.

Okuyama e Martins (1997) utilizaram em sua metodologia o traçado do perfil mole obtido em fotografias de pacientes leucodermas, melanodermas e xantodermas. Os traçados foram avaliados por leigos, Artistas Plásticos e Ortodontistas. Não houve concordância significante entre os grupos de examinadores nas preferências estéticas confirmando a subjetividade desse tipo de análise.

A radiografia lateral da face também já foi utilizada como método de apreciação estética, porém, o ponto de vista clínico ou tegumentar tem vantagem sobre o método radiográfico, pois o tecido mole que recobre o arcabouço esquelético facial é responsável pelas impressões que os indivíduos transmitem em seus contatos sociais (Shaw 1981, Broder et al 1992, Noar 1992).

Desde o início do século passado, os Ortodontistas já se preocupavam em ponderar a estética facial em seus planejamentos terapêuticos (Angle 1907). Bass (1991) relatou que nos tratamentos ortodôntico-cirúrgicos, deve-se levar em consideração a aparência facial em sua totalidade, e não restringir-se aos dentes e bases ósseas maxilares.

Para padronizar as tomadas radiográficas e fotográficas, tornando-as reprodutíveis, diversos autores estudaram a utilização da posição natural da cabeça. A postura mais recomendada foi posicionar os pacientes de pé, olhando para uma parede em frente, exatamente ao nível de seus olhos com o auxilio de um espelho, utilizando ou não um cefalostato para estabilizar a cabeça. Os autores foram concordantes em admitir a confiabilidade e reprodutibilidade dessa posição. (Cooke e Wei 1988, Peng e Cooke 1999, Freire-Maia 2003 e Rino Neto et al 2003).

Reis (2001) fez um estudo de análise facial de uma amostra de 100 adultos normais, que apresentavam selamento labial, utilizando fotos de perfil obtidas com este método, o que permitiu a padronização para efetuar a análise facial numérica do perfil. Realizou também a análise subjetiva do perfil facial determinada por 3 grupos de examinadores (Ortodontistas, Artistas Plásticos e leigos), que classificaram a amostra em esteticamente agradável (3\%), esteticamente aceitável (89\%) e esteticamente desagradável (8\%). 
Phillips et al (1992), testaram a semelhança na avaliação da atratividade facial realizada por 3 grupos de indivíduos, com diferentes níveis de formação profissional (leigos, Ortodontistas e estudantes de Odontologia) utilizando slides. Constataram que houve diferença na avaliação dos 3 grupos, sugerindo que deve-se utilizar um grupo heterogêneo de examinadores para estudos dessa natureza. Quanto à preferência dos observadores por uma das 3 diferentes vistas do paciente (frente, perfil e frente sorrindo), houve variação entre as opiniões. Não houve preferência de uma sobre a outra.

Um fator importante a ser computado é o papel das diferentes estruturas na agradabilidade da face, pois o tratamento ortodôntico-cirúrgico ideal busca características faciais harmonizadas e balanceadas, não se prendendo aos parâmetros rígidos dentários e esqueléticos (Nanda e Ghosh 1997).

Czarnecki et al (1993) pesquisaram o papel do nariz, lábios e mento no perfil facial equilibrado. Observaram que houve preferência para um perfil masculino mais reto e um perfil feminino ligeiramente convexo. As combinações mais desfavoráveis foram as com o mento extremamente retroposto ou com convexidade facial excessiva, representada por um nariz proeminente.

Reis (2001), que também investigou quais estruturas da face foram citadas como responsáveis pela classificação em esteticamente desagradável, encontrou que o nariz foi apontado como o responsável pela estética desagradável em 37\% dos relatos, o mento em 18,9\%, a boca em 5\% e os lábios em 5\%.

\subsection{A fissura $X$ a estética.}

A literatura é escassa nos estudos que avaliam a estética da face em pacientes com fissura, comparando ou não com indivíduos sem fissura. A metodologia que mescla vários tipos de fissura, sem separá-los em grupos, desconsidera as características individuais dos mesmos.

Gaggl et al (1999) fizeram um estudo longitudinal da estética e dos resultados funcionais do tratamento cirúrgico e ortodôntico de pacientes com fissura transforame incisivo bilateral por meio de radiografias cefalométricas e modelos de gesso. Concluíram que, pelo prejuízo no crescimento da face média dos pacientes com fissura 
transforame incisivo bilateral, os melhores resultados só podem ser obtidos pela cirurgia ortognática.

Bertier (2001) verificou a estética de pacientes com fissura pré-forame incisivo unilateral completa, comparando a opinião de 4 grupos de examinadores, sendo fonoaudiólogos; pais e pacientes com a malformação; cirurgiões dentistas; e fisiologistas e geneticistas. Os resultados foram satisfatórios para $70 \%$ dos examinadores, porém deve-se levar em consideração o tipo de fissura, que tem prognóstico mais favorável que a transforame.

Noar (1992) convidou Cirurgiões Plásticos, Fonoaudiólogos e Ortodontistas a dar suas opiniões por meio de questionários, em relação aos adolescentes com fissura unilateral de lábio e palato. Foram investigados quatro aspectos: tratamento, aparência facial e fala, aspectos sociais e emocionais e o sucesso considerado pelos especialistas. Apesar dos profissionais sentirem que obtiveram sucesso, eles não estavam satisfeitos com o resultado do tratamento e nem com a aparência facial e da fala. Eles também sentiram que os pacientes são emocional e socialmente afetados por suas fissuras. Esses profissionais notaram que os pacientes se sentem da mesma forma em relação a eles mesmos sob todos os aspectos.

Roberts-Harry et al (1992) investigaram a classificação da estética facial de pacientes com e sem fissura, comparando a opinião de leigos, Ortodontistas, estudantes de pós-graduação em Ortodontia e clínicos gerais. Na metodologia, foram utilizadas fotografias frontais, e foi solicitado para os examinadores classificar em ordem decrescente do mais agradável para o menos agradável. As avaliações foram repetidas após 2 semanas. Foi observada uma grande concordância na avaliação inter e intraexaminadores. Os autores ressaltaram que o método, para esse tipo de estudo, deve permitir a classificação dos indivíduos sem separá-los em grupos, para não mascarar as variações individuais. No entanto, o estudo mostrou que os pacientes com fissura foram considerados de pior estética facial que os sem fissura, na opinião unânime dos examinadores.

Kapp, em 1979, comparou o auto conceito de 34 crianças com fissura com o mesmo número de crianças sem fissura. Todas as crianças foram avaliadas por meio de questionários objetivos. As crianças com fissura demonstraram uma maior insatisfação com a aparência física em comparação às sem fissura. 
Apesar dos poucos estudos na literatura que julgam a estética facial dos pacientes com fissura, existe um consenso entre os autores de que há insatisfação com os resultados estéticos por parte dos profissionais envolvidos na sua reabilitação, e também dos próprios pacientes. Denota-se portanto, uma necessidade de melhora dos protocolos de tratamento dessa malformação, visando condições finais de harmonia e agradabilidade da face, juntamente com a qualidade dos aspectos funcionais e psicológicos.

Por estas considerações, a estética da face do paciente com fissura transforame incisivo bilateral tratado no HRAC-USP foi alvo deste estudo. 
Objetivos 


\section{OBJETIVOS.}

Avaliar, por meio de fotografias padronizadas e um questionário específico, a estética facial dos pacientes com fissura transforame incisivo bilateral, leucodermas, de ambos os gêneros, que receberam o tratamento cirúrgico de acordo com o protocolo do Hospital de Reabilitação de Anomalias Craniofaciais da Universidade de São Paulo (HRAC-USP), e que estavam na faixa etária de 5 a 10 anos de idade, com o objetivo de:

- classificar a sua agradabilidade facial;

- comparar as classificações dadas pelos diferentes grupos de examinadores (Ortodontistas do HRAC-USP, Ortodontistas não relacionados à área de fissura, Cirurgiões Plásticos do HRAC-USP, Cirurgiões Plásticos não relacionados à área de fissura e leigos com formação superior), verificando a concordância entre as categorias de examinadores e;

- conhecer quais estruturas da face foram reconhecidas como responsáveis pela pior classificação (esteticamente desagradável). 
Material e Método 


\section{MATERIAL E MÉtodo.}

\section{1 - Amostra de pacientes.}

Por tratar-se de um estudo com seres humanos, antes do início do mesmo, o Projeto de Pesquisa foi enviado ao Comitê de Ética em Pesquisa do Hospital de Reabilitação de Anomalias Craniofaciais da Universidade de São Paulo (HRAC-USP), tendo recebido aprovação segundo parecer $n^{0}$ 269/2002 (Anexo 1).

A amostra foi constituída de 30 pacientes, sendo 24 do gênero masculino e 6 do gênero feminino, matriculados no HRAC-USP, leucodermas, com fissura transforame incisivo bilateral, na faixa etária de 5 anos e 8 meses a 10 anos e 4 meses de idade, e média de 7 anos e 10 meses, operados neste hospital. Os pacientes já haviam sido submetidos às cirurgias de lábio (queiloplastia) aos 3,7 meses em média, palato (palatoplastia) aos 16,6 meses em média e, na maioria dos casos, alongamento de columela nasal com 6 anos e 3 meses em média. Não haviam sido tratados ortodonticamente, nem apresentavam síndromes. Foram incluídos na amostra aleatoriamente e consecutivamente, à medida que compareciam ao Hospital para atendimentos, no período de maio a julho de 2004 (Anexos 2 e 3).

Foram utilizados os prontuários de arquivo dos pacientes para obtenção de dados relativos ao tratamento recebido e preenchimento da ficha clínica (Anexo 4).

Todos os responsáveis pelos participantes da amostra assinaram o termo de consentimento livre e esclarecido que se encontra no Anexo 5.

\section{2 - Método de obtenção das fotografias.}

Foram obtidas fotografias dos perfis faciais direito e esquerdo, utilizando câmera fotográfica digital, adaptada a um suporte de metal articulado e preso à parede pela estativa de madeira. A análise de perfil foi escolhida por ser um dos parâmetros para 
diagnóstico e planejamento ortodôntico-cirúrgico. Os pacientes foram posicionados de pé, estabilizados em um cefalostato de metal preso na parede, com as olivas adaptadas passivamente no conduto auditivo externo dos mesmos. Para padronização das fotografias, foram instruídos a olhar de frente para um espelho inclinado, em posição natural da cabeça (Cooke e Wei 1988, Peng e Cooke 1999, Freire-Maia 2003 e Rino Neto et al 2003). Foi utilizado um flash com sombrinha e tripé posicionado atrás da câmera fotográfica. Uma caixa de luz foi colocada atrás do paciente para evitar sombras nas fotografias. Além disso, uma linha de nylon presa a um prumo metálico foi adaptada à caixa de luz para representar a linha vertical verdadeira e auxiliar no recorte das fotografias, evitando que o perfil ficasse com inclinação errada em relação ao solo (figuras 3 a 10).

\begin{tabular}{|l|l|}
\hline Câmera digital & Coolpix 995 Nikon \\
\hline Modo (M) & manual \\
\hline Ajuste de abertura (f) & 9.3 \\
\hline Ajuste de velocidade & $1 / 125$ segundos \\
\hline Qualidade de imagem & Normal \\
\hline Tamanho da imagem & UXGA (1600 X 1200 pixels) \\
\hline Ajuste de sensibilidade & ASA 100 \\
\hline flash & ligado \\
\hline
\end{tabular}

Figura 3 -Especificações da máquina fotográfica 


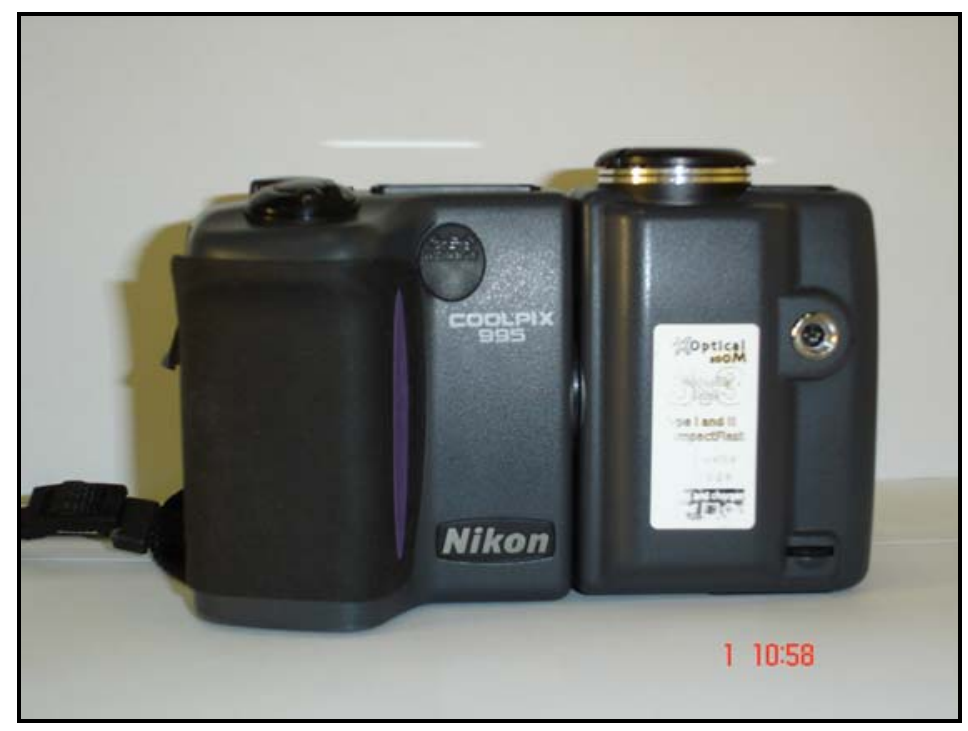

Figura 4 - Câmera digital Coolpix 995 Nikon

\begin{tabular}{|l|l|}
\hline Material & madeira, recoberta por um tecido de malha fina branca \\
\hline \multirow{2}{*}{ Medidas } & $\begin{array}{l}.1,87 \mathrm{~m} \text { de altura } \\
.0,80 \mathrm{~m} \text { de largura } \\
.0,12 \mathrm{~m} \text { profundidade }\end{array}$ \\
\hline Posicionamento & base a 0,51m do chão \\
\hline Lâmpadas & 6 lâmpadas fluorescentes OSRAM L 58 W/21-84 COCL White (Germany) \\
\hline
\end{tabular}

m - metro

Figura 5 -Especificações da caixa de luz

\begin{tabular}{|l|l|}
\hline Tipo & Atek Flash System bivolt 160 plus \\
\hline Lâmpada & 100 W/127 V GE \\
\hline Tripé & UN82 CADETE \\
\hline
\end{tabular}

W - watt

Figura 6 - Especificações do flash com sombrinha 


\begin{tabular}{|c|c|}
\hline Distância da câmera à parede que fixa a estativa & $0,56 \mathrm{~m}$ \\
\hline Distância da câmera ao paciente & $0,87 \mathrm{~m}$ \\
\hline Distância do flash com sombrinha ao paciente & $1,30 \mathrm{~m}$ \\
\hline Distância da caixa de luz ao paciente & $0,80 \mathrm{~m}$ \\
\hline Distância do espelho ao paciente & $0,65 \mathrm{~m}$ \\
\hline Variação vertical do cefalostato & de $1,07 \mathrm{~m}$ à 2, $20 \mathrm{~m}$ \\
\hline Variação vertical do flash com sombrinha & de $0,97 \mathrm{~m}$ à $1,75 \mathrm{~m}$ \\
\hline Variação vertical da câmera (estativa) & $1,02 \mathrm{~m}$ à 2,18 m \\
\hline Especificações da linha vertical verdadeira & $\begin{array}{l}\text { f feita de nylon } \\
\text {. com prumo (peso) na extremidade } \\
\text {. articulada } \\
\text {. posicionada à } 2,38 \text { m do chão }\end{array}$ \\
\hline Especificações do espelho & $\begin{array}{l}\text {. 0,20 m X 0,30 m } \\
\text {. fixado com ímã na parede metálica } \\
\text {. posicionado inclinado } \\
\text {. na altura dos olhos do paciente }\end{array}$ \\
\hline
\end{tabular}

m - metro

Figura 7 -Especificações para obtenção das fotografias
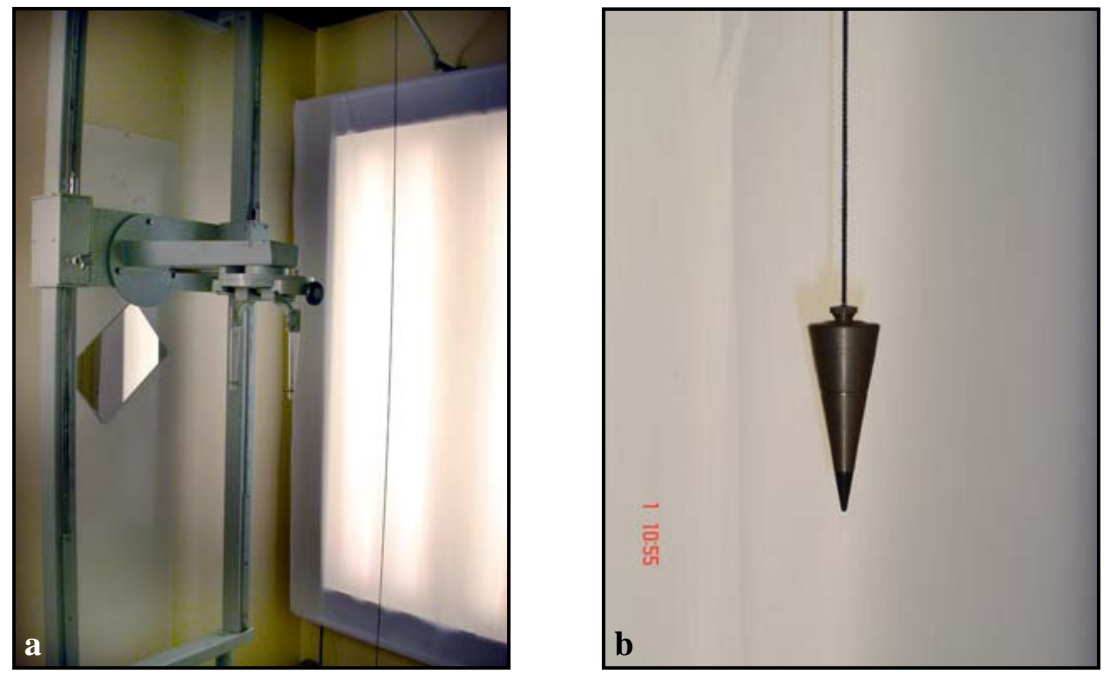

Figura 8 - a) Cefalostato, caixa de luz, espelho e linha vertical verdadeira; b) detalhe do prumo preso à ponta da linha vertical verdadeira 


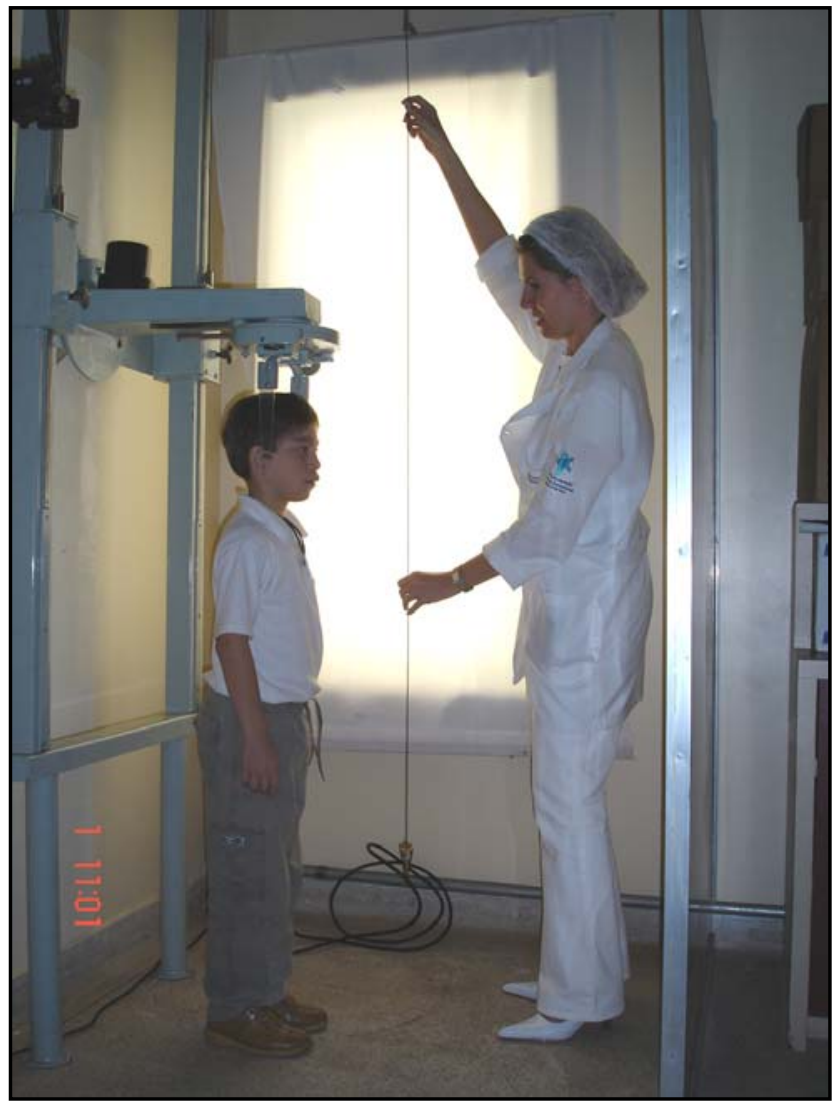

Figura 9 - Posicionamento da linha vertical verdadeira à frente do paciente
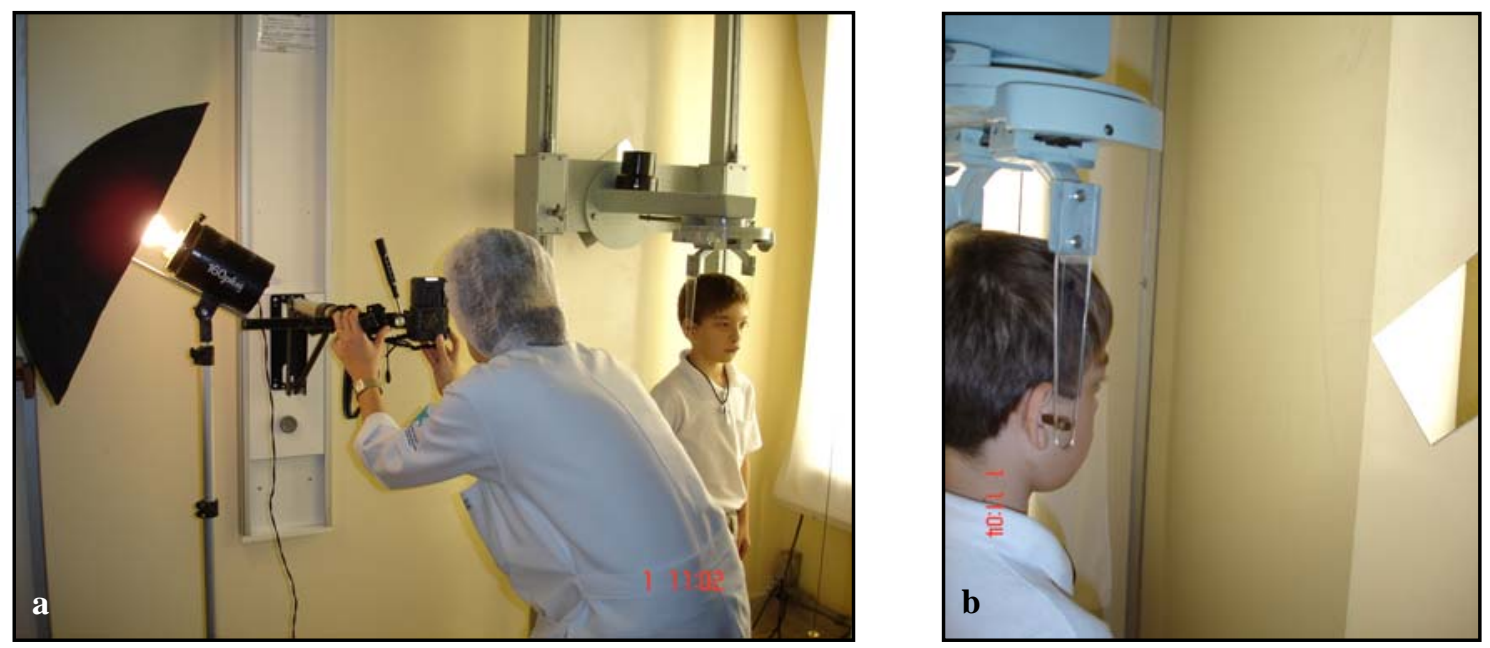

Figura 10 - a) Tomada fotográfica com o paciente posicionado no cefalostato e a caixa de luz acesa; b) Posicionamento adequado do paciente frente ao espelho inclinado 


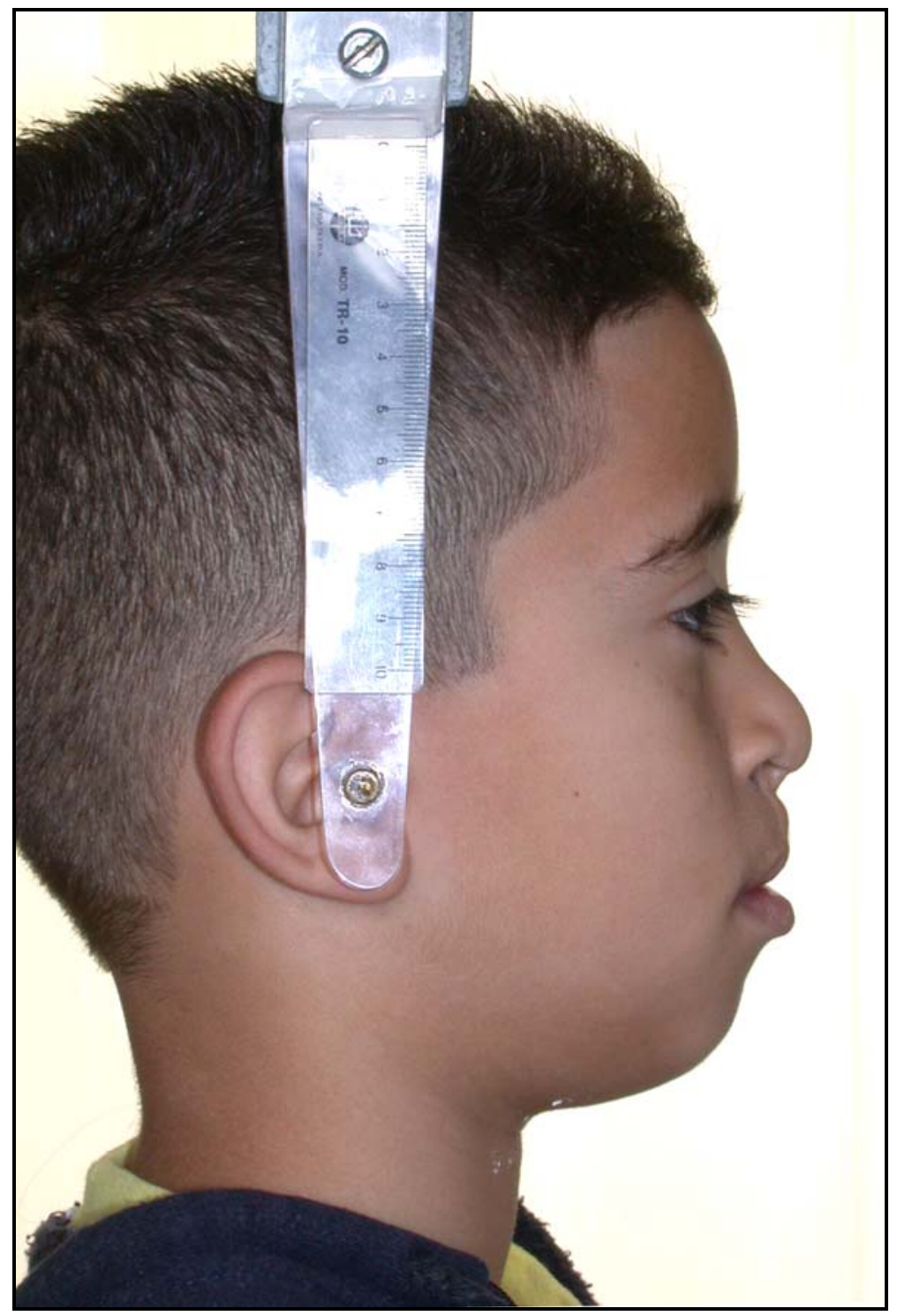

Figura 11 - Fotografia do perfil direito em tamanho real $(10$ x 15 cm) 


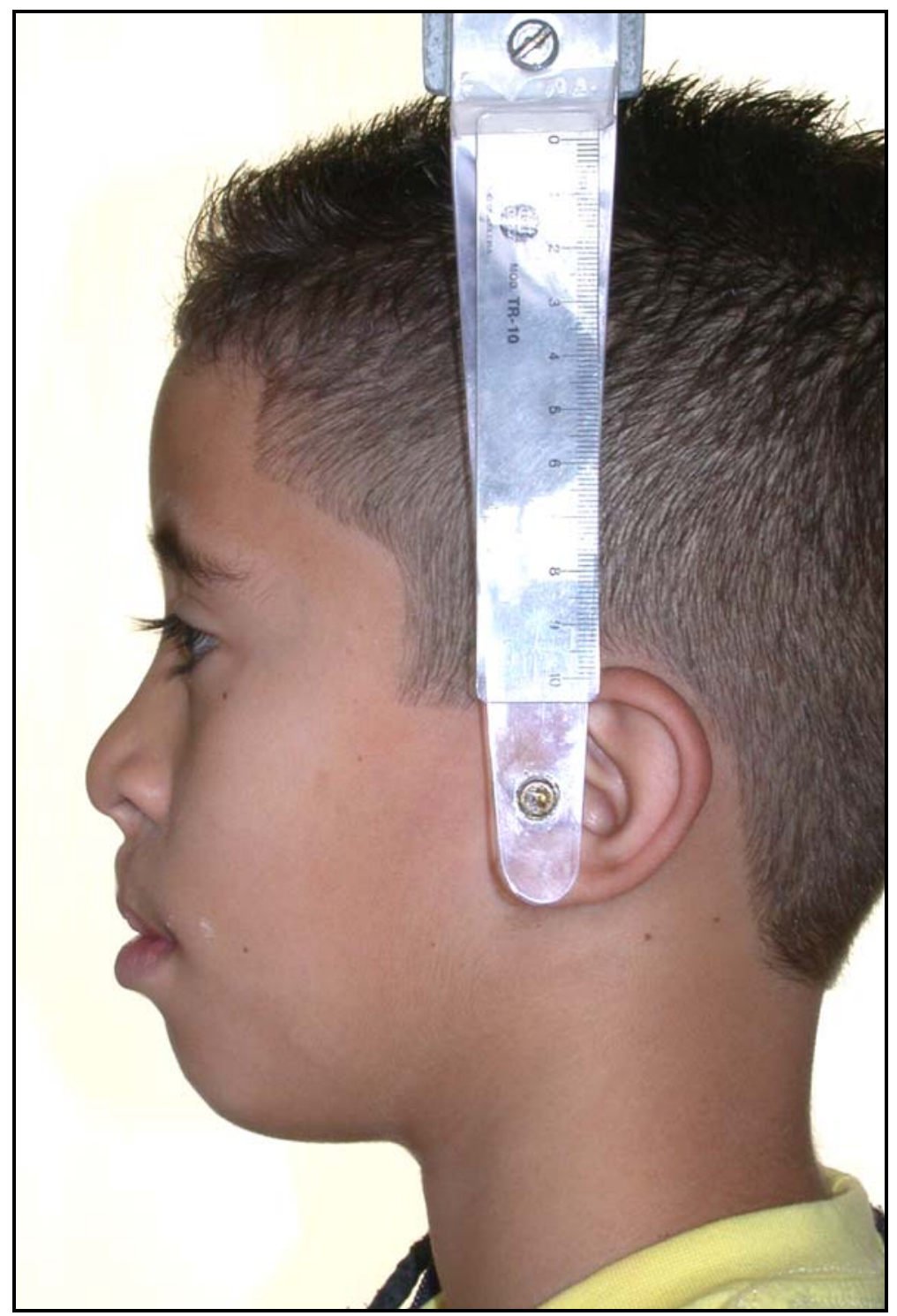

Figura 12- Fotografia do perfil esquerdo em tamanho real $(10 \times 15 \mathrm{~cm})$

As fotografias digitais dos perfis direito e esquerdo foram ampliadas em papel fotográfico brilhante no tamanho 10 X 15cm (figuras 11 e 12). As ampliações foram feitas em laboratório digital comercial da cidade de Bauru (Hobby Foto). Posteriormente foram organizadas em álbuns para a visualização dos examinadores. 


\section{3 - Examinadores.}

Os examinadores foram divididos em 5 grupos: 5 Ortodontistas do HRAC-USP, 5 Ortodontistas não relacionados à área de fissura, 5 Cirurgiões Plásticos do HRACUSP, 5 Cirurgiões Plásticos não relacionados à área de fissura, 5 leigos com formação superior, num total de 25 pessoas, sendo 13 do gênero masculino e 12 do gênero feminino. A amostra de examinadores foi escolhida por conveniência devido à dificuldade de se conseguir uma amostra aleatória. Os Ortodontistas não relacionados à área de fissura eram pertencentes à Pós-Graduação da Faculdade de Odontologia de Bauru da USP e os Cirurgiões Plásticos não relacionados à área de fissura participavam da Pós-Graduação da Faculdade de Medicina de São Paulo da USP. O grupo de leigos com formação superior foi formado por um engenheiro civil, um agrônomo, um veterinário e duas advogadas.

Os 5 grupos atribuíram notas em 2 avaliações. Para a $1^{\text {a }}$ avaliação, os álbuns foram entregues aos examinadores e estes foram instruídos a avaliar as fotografias por 30 segundos e dar escores aos pacientes, preenchendo um questionário específico com a seguinte orientação: a) esteticamente agradável (notas 7, 8 e 9); b) esteticamente aceitável (notas 4, 5 e 6); c) esteticamente desagradável (notas 1, 2 e 3). Caso as notas fossem 1, 2 ou 3, pediu-se para descrever o motivo pelo qual o indivíduo foi considerado esteticamente desagradável, conforme Reis (2001) (Anexos 6 e 7).

Nessa etapa os examinadores não sabiam que iriam realizar uma $2^{\mathrm{a}}$ avaliação com a intenção de se verificar a concordância intra-examinador.

A $2^{\mathrm{a}}$ avaliação foi feita entre 15 a 30 dias após a $1^{\mathrm{a}}$, e as mesmas instruções foram dadas.

\section{4 - Análise estatística.}

Os dados foram analisados por meio de tabelas e gráficos contendo freqüência absoluta e relativa, média, mediana, $1^{0}$. quartil, $3^{\circ}$. quartil, valor mínimo e valor máximo dos escores atribuídos pelos examinadores.

Para verificar a concordância entre os examinadores de uma mesma categoria utilizou-se o Coeficiente de Concordância de Kendall (W). 
Para verificar a concordância intra-examinador nas duas avaliações foi utilizado o Coeficiente de Correlação de Spearman $\left(\mathrm{r}_{\mathrm{s}}\right)$.

Para representar os escores de cada uma das categorias foi feita a mediana dos 5 examinadores de cada categoria. Deu-se preferência ao uso da mediana pelas notas atribuídas serem consideradas escores, e tendo-se 5 examinadores em cada categoria, a mediana entre eles sempre resulta em um valor inteiro da escala de 1 a 9 , o que não aconteceria caso se utilizasse a média dos mesmos.

Para verificar a concordância entre as categorias utilizou-se o Coeficiente de Concordância de Kendall (W).

Para comparar se as categorias tiveram tendência em atribuir escores mais altos ou baixos umas das outras utilizou-se o teste de Friedman, este acusando diferença estatisticamente significante foi utilizado o teste de Student-Newman-Keuls para as comparações múltiplas.

Em todos os testes foi adotado nível de significância de 5\% $(\mathrm{p}<0,05)$.

Todos os cálculos estatísticos foram executados no programa Statistica for Windows versão 5.1, da StatSoft Inc. Tulsa, USA.

Os testes estatísticos foram descritos por Siegel (1956) e Zar (1996) . 
Resultados 


\section{RESULTADOS.}

Os resultados apresentados a seguir foram obtidos a partir dos escores atribuídos pelos examinadores aos sujeitos da amostra. Os escores individuais imputados pelos 5 grupos de examinadores na $1^{\mathrm{a}}$ avaliação encontram-se no Anexo 8, e os da $2^{\mathrm{a}}$ avaliação no Anexo 9. Para a análise geral de cada categoria de examinador foi utilizada a mediana dos 5 examinadores para cada paciente.

A tabela 1 mostra a média, a mediana, o $1^{0}$ quartil, o $3^{\circ}$ quartil, o mínimo e o máximo dos escores atribuídos aos 30 pacientes avaliados pelos 25 examinadores na $1^{\mathrm{a}}$ avaliação, e a tabela 2 mostra esses dados equivalentes à $2^{a}$ avaliação. 
Tabela 1 - Média, mediana, $1^{0}$ quartil, $3^{0}$ quartil, mínimo e máximo dos escores atribuídos pelos 25 examinadores na $1^{\mathrm{a}}$ avaliação

\begin{tabular}{|c|c|c|c|c|c|c|}
\hline Categoria & média & mediana & $1^{\circ}$ quartil & $3^{\circ}$ quartil & mínimo & máximo \\
\hline CPNF 1 & 3,4 & 3 & 3 & 4 & 2 & 5 \\
\hline CPNF 2 & 3,0 & 3 & 2 & 4 & 1 & 6 \\
\hline CPNF 3 & 2,9 & 3 & 2 & 4 & 1 & 4 \\
\hline CPNF 4 & 2,9 & 3 & 2 & 4 & 1 & 4 \\
\hline CPNF 5 & 3,4 & 3 & 3 & 4 & 1 & 6 \\
\hline CPNF geral & 3,2 & 3 & 3 & 4 & 1 & 5 \\
\hline CPHRAC 1 & 4,3 & 4,5 & 3 & 5 & 3 & 6 \\
\hline CPHRAC 2 & 5,5 & 6 & 4 & 6 & 4 & 8 \\
\hline CPHRAC 3 & 4,4 & 4 & 3 & 5 & 3 & 7 \\
\hline CPHRAC 4 & 6,7 & 7 & 6 & 8 & 4 & 9 \\
\hline CPHRAC 5 & 4,8 & 5 & 4 & 5 & 1 & 7 \\
\hline CPHRAC geral & 5,1 & 5 & 4 & 6 & 3 & 7 \\
\hline ONF 1 & 2,8 & 3 & 2 & 4 & 1 & 6 \\
\hline ONF 2 & 3,4 & 3 & 3 & 4 & 2 & 6 \\
\hline ONF 3 & 4,2 & 4 & 4 & 5 & 2 & 7 \\
\hline ONF 4 & 3,2 & 3 & 3 & 4 & 2 & 6 \\
\hline ONF 5 & 2,2 & 2 & 1 & 3 & 1 & 4 \\
\hline ONF geral & 3,2 & 3 & 3 & 4 & 2 & 5 \\
\hline OHRAC 1 & 6,2 & 6,5 & 5 & 8 & 1 & 9 \\
\hline OHRAC 2 & 6,0 & 6 & 5 & 7 & 3 & 8 \\
\hline OHRAC 3 & 6,6 & 7 & 6 & 8 & 4 & 8 \\
\hline OHRAC 4 & 7,2 & 7 & 7 & 8 & 5 & 8 \\
\hline OHRAC 5 & 5,6 & 6 & 5 & 7 & 1 & 9 \\
\hline OHRAC geral & 6,4 & 7 & 6 & 7 & 3 & 8 \\
\hline L 1 & 4,1 & 4 & 3 & 5 & 3 & 7 \\
\hline L 2 & 3,4 & 3 & 3 & 4 & 3 & 6 \\
\hline L 3 & 3,1 & 3 & 3 & 3 & 3 & 4 \\
\hline L 4 & 5,0 & 5 & 4 & 6 & 4 & 8 \\
\hline L 5 & 6,2 & 6 & 5 & 7 & 4 & 9 \\
\hline L geral & 4,0 & 4 & 3 & 5 & 3 & 7 \\
\hline
\end{tabular}

CPNF - Cirurgiões Plásticos não relacionados à área de fissura

CPHRAC - Cirurgiões Plásticos do HRAC-USP

ONF - Ortodontistas não relacionados à área de fissura

OHRAC - Ortodontistas do HRAC-USP

$\mathrm{L}$ - Leigos com formação superior 
Tabela 2 - Média, mediana, $1^{\circ}$ quartil, $3^{\circ}$ quartil, mínimo e máximo dos escores atribuídos pelos 25 examinadores na $2^{\mathrm{a}}$ avaliação

\begin{tabular}{|c|c|c|c|c|c|c|}
\hline Categoria & média & mediana & $1^{\circ}$ quartil & $3^{\circ}$ quartil & mínimo & máximo \\
\hline CPNF 1 & 3,1 & 3 & 3 & 3 & 2 & 4 \\
\hline CPNF 2 & 2,4 & 3 & 2 & 3 & 1 & 4 \\
\hline CPNF 3 & 2,6 & 3 & 1 & 3 & 1 & 5 \\
\hline CPNF 4 & 2,7 & 3 & 2 & 3 & 2 & 3 \\
\hline CPNF 5 & 3,3 & 3 & 3 & 4 & 2 & 5 \\
\hline CPNF geral & 2,8 & 3 & 3 & 3 & 2 & 4 \\
\hline CPHRAC 1 & 4,3 & 4 & 3 & 6 & 3 & 6 \\
\hline CPHRAC 2 & 5,6 & 6 & 5 & 6 & 4 & 8 \\
\hline CPHRAC 3 & 5,4 & 5 & 4 & 6 & 3 & 8 \\
\hline CPHRAC 4 & 6,0 & 6 & 5 & 7 & 4 & 7 \\
\hline CPHRAC 5 & 5,6 & 6 & 4 & 7 & 2 & 9 \\
\hline CPHRAC geral & 5,4 & 6 & 4 & 6 & 3 & 7 \\
\hline ONF 1 & 4,1 & 4 & 3 & 5 & 3 & 7 \\
\hline ONF 2 & 3,2 & 3 & 3 & 4 & 2 & 5 \\
\hline ONF 3 & 4,2 & 4 & 4 & 5 & 2 & 6 \\
\hline ONF 4 & 2,9 & 3 & 2 & 3 & 1 & 5 \\
\hline ONF 5 & 3,1 & 3 & 3 & 4 & 1 & 4 \\
\hline ONF geral & 3,4 & 3 & 3 & 4 & 2 & 5 \\
\hline OHRAC 1 & 5,9 & 6 & 5 & 7 & 2 & 9 \\
\hline OHRAC 2 & 5,9 & 6 & 5 & 7 & 4 & 8 \\
\hline OHRAC 3 & 7,0 & 7 & 7 & 8 & 4 & 9 \\
\hline OHRAC 4 & 6,8 & 7 & 6 & 7 & 4 & 8 \\
\hline OHRAC 5 & 4,4 & 4 & 3 & 5 & 1 & 7 \\
\hline OHRAC geral & 6,2 & 6 & 6 & 7 & 4 & 8 \\
\hline L 1 & 4,2 & 4 & 4 & 5 & 3 & 6 \\
\hline L 2 & 3,6 & 3 & 3 & 4 & 3 & 7 \\
\hline L 3 & 3,3 & 3 & 3 & 4 & 3 & 4 \\
\hline L 4 & 5,6 & 6 & 5 & 6 & 5 & 7 \\
\hline L 5 & 5,8 & 6 & 5 & 7 & 4 & 8 \\
\hline L geral & 4,2 & 4 & 4 & 5 & 3 & 6 \\
\hline
\end{tabular}

CPNF - Cirurgiões Plásticos não relacionados à área de fissura

CPHRAC - Cirurgiões Plásticos do HRAC-USP

ONF - Ortodontistas não relacionados à área de fissura

OHRAC - Ortodontistas do HRAC-USP

L - Leigos com formação superior 
Para ilustrar os escores atribuídos por paciente, a seguir são mostrados fotografias dos pacientes que obtiveram escore médio geral (considerando-se os 25 examinadores): Mais alto (6,2), intermediário $(4,4)$, e mais baixo $(2,8)$, respectivamente, figuras 13, 14 e 15.
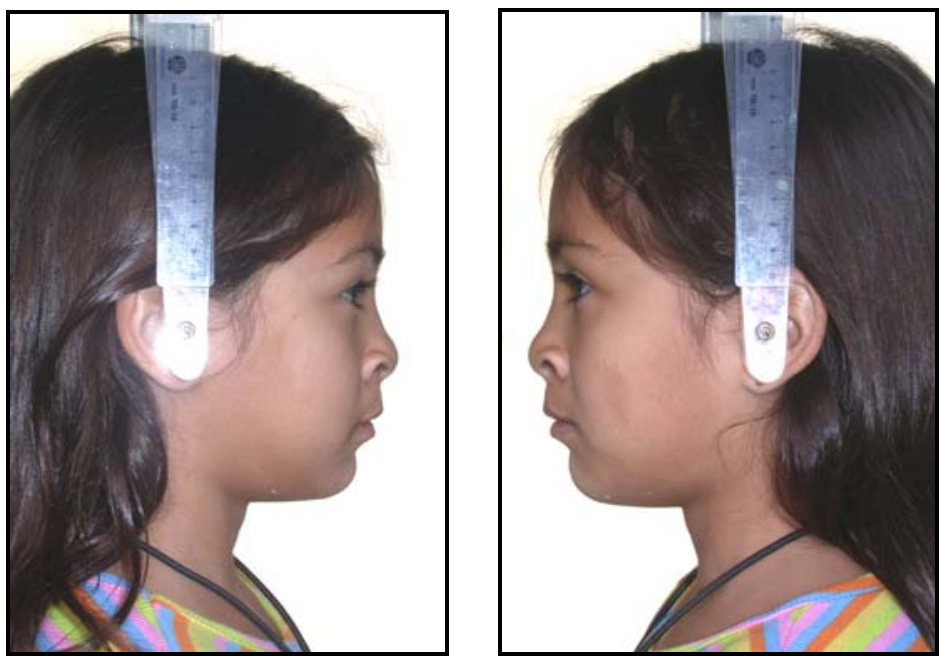

Figura 13 - Paciente que obteve escore mais alto $(6,2)$
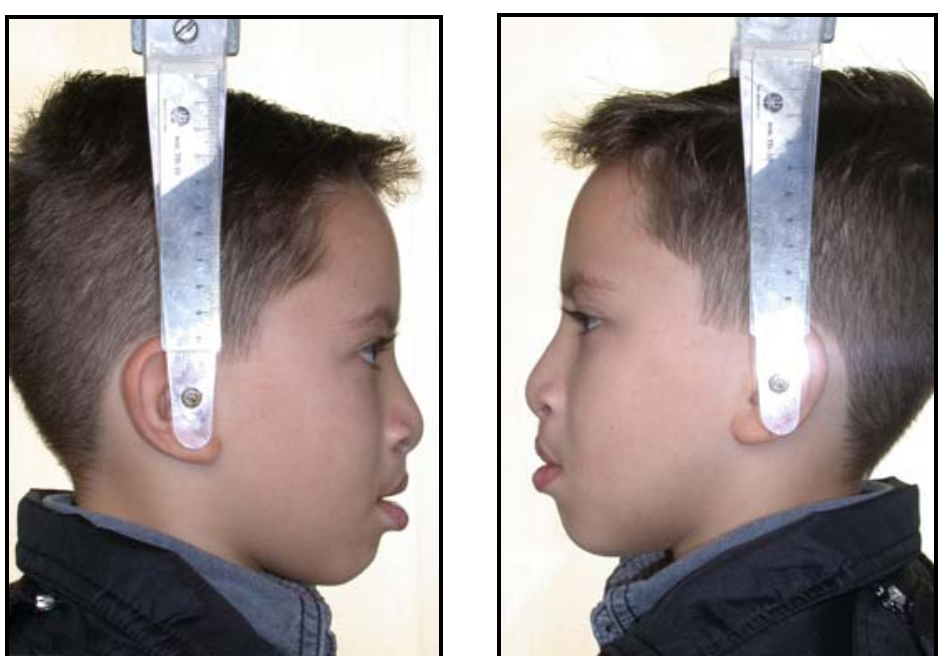

Figura 14 - Paciente que obteve escore intermediário $(4,4)$ 

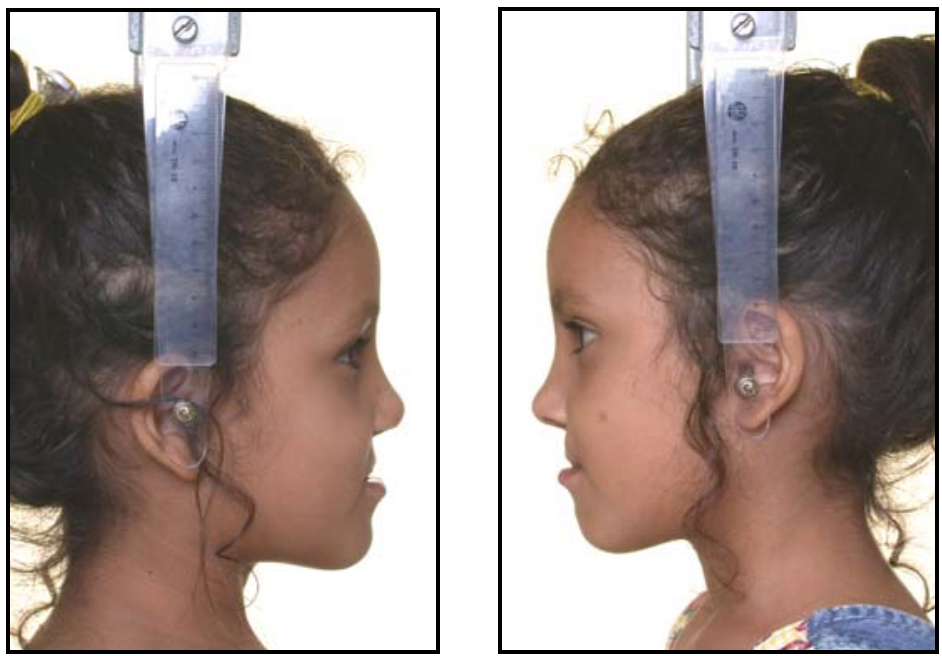

Figura 15 - Paciente que obteve escore mais baixo $(2,8)$

\subsection{Concordância intra e inter-examinadores.}

Os escores atribuídos pelos examinadores foram comparadas entre si para verificar a concordância inter-examinadores de cada categoria. A tabela 3 demonstra o Coeficiente de Concordância de Kendall (W) entre os examinadores de cada categoria na $1^{\text {a }}$ avaliação e a tabela 4 os valores correspondentes obtidos na $2^{\text {a }}$ avaliação.

O Coeficiente de Concordância de Kendall indicou que existiu concordância estatisticamente significante dentro de todas categorias nas duas avaliações. Levando-se em conta que este coeficiente pode variar de 0 a 1 observou-se que ele se situou na faixa de 0,46 a 0,74 indicando uma concordância de média a forte. 
Tabela 3 - Coeficiente de Concordância de Kendall (W) entre os examinadores de cada categoria na $1^{\mathrm{a}}$ avaliação

\begin{tabular}{lcc}
\hline Categoria & $\mathrm{W}$ & $\mathrm{p}$ \\
\hline CPNF & 0,64 & $0,000^{*}$ \\
CPHRAC & 0,57 & $0,000^{*}$ \\
ONF & 0,64 & $0,000^{*}$ \\
OHRAC & 0,74 & $0,000^{*}$ \\
L & 0,55 & $0,000^{*}$ \\
\hline
\end{tabular}

Nota: * - concordância estatisticamente significante $(\mathrm{p}<0,05)$ $\mathrm{p}$ - probabilidade

CPNF - Cirurgiões Plásticos não relacionados à área de fissura CPHRAC - Cirurgiões Plásticos do HRAC-USP

ONF - Ortodontistas não relacionados à área de fissura

OHRAC - Ortodontistas do HRAC-USP

$\mathrm{L}$ - Leigos com formação superior

Tabela 4 - Coeficiente de Concordância de Kendall (W) entre os examinadores de cada categoria na $2^{\mathrm{a}}$ avaliação

\begin{tabular}{lcc}
\hline Categoria & $\mathrm{W}$ & $\mathrm{p}$ \\
\hline CPNF & 0,46 & $0,000^{*}$ \\
CPHRAC & 0,56 & $0,000^{*}$ \\
ONF & 0,68 & $0,000^{*}$ \\
OHRAC & 0,63 & $0,000^{*}$ \\
L & 0,51 & $0,000^{*}$ \\
\hline
\end{tabular}

Nota: * - concordância estatisticamente significante $(\mathrm{p}<0,05)$ $\mathrm{p}$ - probabilidade

CPNF - Cirurgiões Plásticos não relacionados à área de fissura CPHRAC - Cirurgiões Plásticos do HRAC-USP

ONF - Ortodontistas não relacionados à área de fissura

OHRAC - Ortodontistas do HRAC-USP

$\mathrm{L}$ - Leigos com formação superior

Para verificar a concordância intra-examinador foi utilizado o Coeficiente de Correlação de Spearman $\left(r_{s}\right)$ entre a $1^{\mathrm{a}}$ e $2^{\mathrm{a}}$ avaliação de cada um dos 25 examinadores (tabela 5). 
Verificou-se correlação estatisticamente significante para todos examinadores, exceto o examinador 4 da categoria CPNF sendo que este ficou próximo do valor de significância estatística $(\mathrm{p}=0,087)$.

Tabela 5 - Coeficiente de Correlação de Spearman $\left(\mathrm{r}_{\mathrm{s}}\right)$ entre a $1^{\mathrm{a}}$ e $2^{\mathrm{a}}$ avaliação de cada um dos 25 examinadores

\begin{tabular}{|c|c|c|}
\hline Examinadores & $r_{s}$ & $\mathrm{p}$ \\
\hline CPNF 1 & 0,47 & $0,009 *$ \\
\hline CPNF 2 & 0,72 & $0,000^{*}$ \\
\hline CPNF 3 & 0,49 & $0,006^{*}$ \\
\hline CPNF 4 & 0,32 & $0,087 \mathrm{~ns}$ \\
\hline CPNF 5 & 0,64 & $0,000 *$ \\
\hline $\begin{array}{l}\text { CPHRAC } 1 \\
\end{array}$ & 0,86 & $0,000^{*}$ \\
\hline CPHRAC 2 & 0,50 & $0,005^{*}$ \\
\hline CPHRAC 3 & 0,55 & $0,002 *$ \\
\hline CPHRAC 4 & 0,57 & $0,001^{*}$ \\
\hline CPHRAC 5 & 0,75 & $0,000 *$ \\
\hline ONF 1 & 0,68 & $0,000^{*}$ \\
\hline ONF 2 & 0,72 & $0,000^{*}$ \\
\hline ONF 3 & 0,71 & $0,000^{*}$ \\
\hline ONF 4 & 0,86 & $0,000 *$ \\
\hline ONF 5 & 0,56 & $0,001^{*}$ \\
\hline$\overline{\text { OHRAC } 1}$ & 0,81 & $0,000^{*}$ \\
\hline OHRAC 2 & 0,52 & $0,003^{*}$ \\
\hline OHRAC 3 & 0,66 & $0,000^{*}$ \\
\hline OHRAC 4 & 0,71 & $0,000^{*}$ \\
\hline OHRAC 5 & 0,86 & $0,000^{*}$ \\
\hline L 1 & 0,64 & $0,000^{*}$ \\
\hline L 2 & 0,57 & $0,001^{*}$ \\
\hline L 3 & 0,43 & $0,018^{*}$ \\
\hline L 4 & 0,41 & $0,024 *$ \\
\hline L 5 & 0,69 & $0,000^{*}$ \\
\hline \multicolumn{3}{|c|}{$\begin{array}{l}\text { Nota: * - correlação estatisticamente significante }(\mathrm{p}<0,05) \\
\text { ns - correlação estatisticamente não significante } \\
\text { p - probalilidade } \\
\text { CPNF - Cirurgiões Plásticos não relacionados à área de fissur } \\
\text { CPHRAC - Cirurgiões Plásticos do HRAC-USP } \\
\text { ONF - Ortodontistas não relacionados à área de fissura } \\
\text { OHRAC - Ortodontistas do HRAC-USP } \\
\text { L - Leigos com formação superior }\end{array}$} \\
\hline
\end{tabular}


Conforme demonstrado pelos testes acima, houve uma concordância aceitável tanto entre os examinadores, como entre a $1^{\mathrm{a}}$ e a $2^{\mathrm{a}}$ avaliação, estabelecendo uma confiabilidade do método.

\subsection{Comparação dos escores atribuídos por categoria de examinador.}

Para as comparações entre as categorias utilizou-se os dados da $1^{\mathrm{a}}$ avaliação visto que a $2^{\mathrm{a}}$ avaliação foi feita com intuito de se verificar a reprodutibilidade da avaliação por meio de sua correlação. Utilizou-se como valor de cada categoria a mediana dos escores atribuídos pelos 5 examinadores de cada uma.

Para verificar a concordância entre (inter) categorias utilizou-se o Coeficiente de Concordância de Kendall (W) cujo resultado está mostrado na tabela 6.

O resultado mostra que houve concordância estatisticamente significante entre as categorias, situando-se o valor do coeficiente de concordância na faixa de médio a forte.

Tabela 6 - Coeficiente de Concordância de Kendall (W) entre as 5 categorias

\begin{tabular}{lc}
\hline $\mathrm{W}$ & $\mathrm{p}$ \\
\hline 0,65 & $0,000^{*}$ \\
\hline $\begin{array}{l}\text { Nota: * - concordância estatisticamente significante }(\mathrm{p}<0,05) \\
\mathrm{p}-\text { probabilidade }\end{array}$
\end{tabular}

É importante salientar que um coeficiente de concordância de médio a forte indica que as categorias têm uma razoável concordância quanto a classificação dos piores para os melhores casos, sendo que os escores atribuídos não necessariamente sejam parecidos (tabela 7). 
Tabela 7 - Mediana das avaliações por categoria de examinador

\begin{tabular}{lc}
\hline Categoria & mediana \\
\hline OHRAC & 7 \\
CPHRAC & 5 \\
L & 4 \\
CPNF e ONF & 3 \\
\hline
\end{tabular}

CPNF - Cirurgiões Plásticos não relacionados à área de fissura CPHRAC - Cirurgiões Plásticos do HRAC-USP

ONF - Ortodontistas não relacionados à área de fissura

OHRAC - Ortodontistas do HRAC-USP

L - Leigos com formação superior

A tabela 8 resume os resultados atribuídos pelas 5 categorias, e a figura16 ilustra estes dados.

Tabela 8 - Média, mediana, $1^{\circ}$ quartil, $3^{\circ}$ quartil, mínimo e máximo dos escores atribuídos por categoria

\begin{tabular}{|c|c|c|c|c|c|c|}
\hline Categoria & média & mediana & $1^{\circ}$ quartil & $3^{\circ}$ quartil & mínimo & máximo \\
\hline CPNF & 3,2 & 3 & 3 & 4 & 1 & 5 \\
\hline CPHRAC & 5,1 & 5 & 4 & 6 & 3 & 7 \\
\hline ONF & 3,2 & 3 & 3 & 4 & 2 & 5 \\
\hline OHRAC & 6,4 & 7 & 6 & 7 & 3 & 8 \\
\hline $\mathrm{L}$ & 4,0 & 4 & 3 & 5 & 3 & 7 \\
\hline
\end{tabular}

CPNF - Cirurgiões Plásticos não relacionados à área de fissura

CPHRAC - Cirurgiões Plásticos do HRAC-USP

ONF - Ortodontistas não relacionados à área de fissura

OHRAC - Ortodontistas do HRAC-USP

$\mathrm{L}$ - Leigos com formação superior 


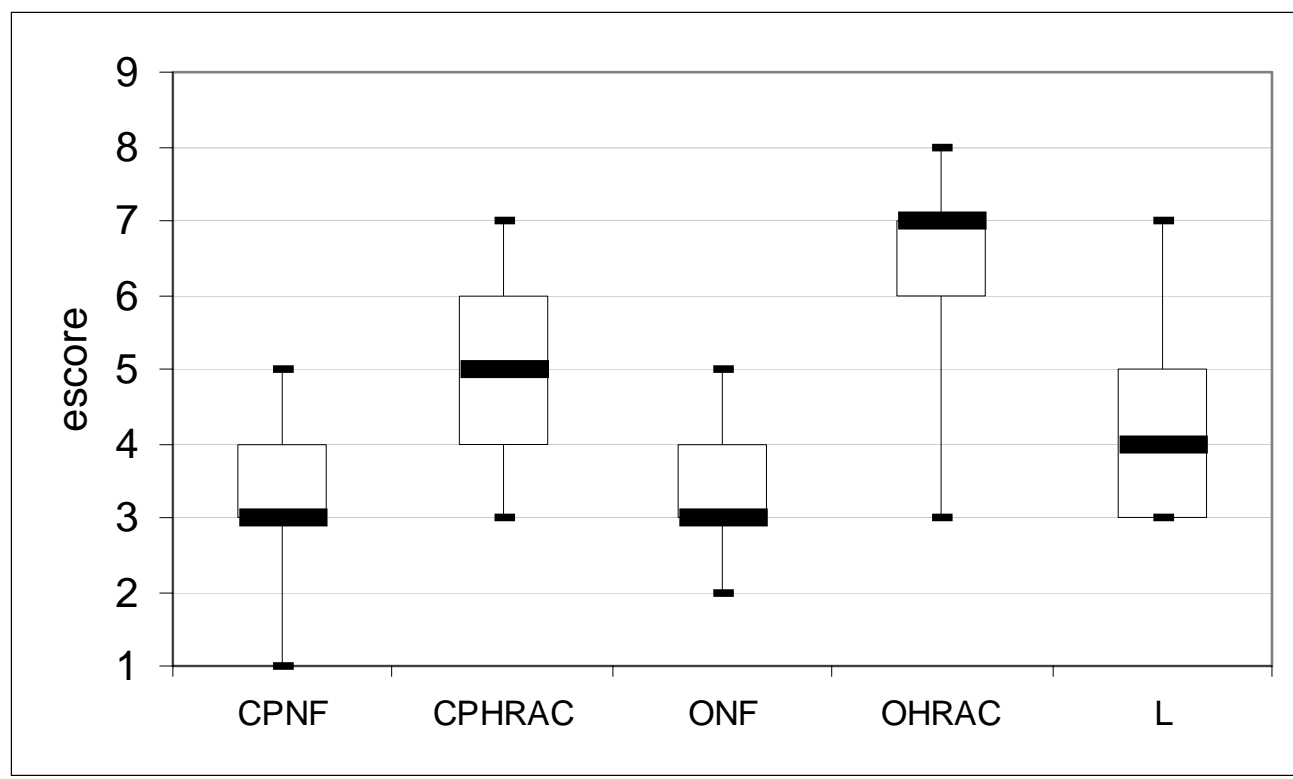

CPNF - Cirurgiões Plásticos não relacionados à área de fissura CPHRAC - Cirurgiões Plásticos do HRAC-USP

ONF - Ortodontistas não relacionados à área de fissura OHRAC - Ortodontistas do HRAC-USP

L - Leigos com formação superior

Figura 16 - Valores da mediana, $1^{0}$.quartil, $3^{\circ}$. quartil, mínimo e máximo por categoria

Pelos resultados identificou-se que os Ortodontistas do HRAC (OHRAC) foram os que atribuíram os maiores escores, seguidos dos Cirurgiões Plásticos do HRAC, (CPHRAC), depois dos leigos com formação superior (L) e por fim os Ortodontistas não relacionados à área de fissura $(\mathrm{ONF})$ e os Cirurgiões Plásticos não relacionados à área de fissura (CPNF).

Para verificar se houve diferença estatisticamente significante, entre as categorias, foi utilizado o teste não paramétrico de Friedman e este mostrou diferença estatisticamente significante entre as elas $(\chi 2=45,95 ; \mathrm{p}=0,000)$. O teste de StudentNewman-Keuls para as comparações múltiplas identificou diferenças significantes entre todas categorias exceto entre ONF e CPNF.

Como o trabalho de Reis (2001) sugeriu a distribuição dos escores de 1 a 3 na classificação Desagradável, de 4 a 6 em Aceitável, e de 7 a 9 em Agradável, isto foi feito e os resultados estão mostrados nas tabelas 9 e 10 e figura 17. 
Tabela 9 - Distribuição das classificações atribuídas pelos 25 examinadores

\begin{tabular}{|c|c|c|c|c|c|c|}
\hline \multirow{2}{*}{ Examinador } & \multicolumn{2}{|c|}{ Desagradável } & \multicolumn{2}{|c|}{ Aceitável } & \multicolumn{2}{|c|}{ Agradável } \\
\hline & $\mathrm{n}$ & $\%$ & $\mathrm{~N}$ & $\%$ & $\mathrm{n}$ & $\%$ \\
\hline CPNF 1 & 19 & 63,3 & 11 & 36,7 & 0 & 0,0 \\
\hline CPNF 2 & 22 & 73,3 & 8 & 26,7 & 0 & 0,0 \\
\hline CPNF 3 & 21 & 70,0 & 9 & 30,0 & 0 & 0,0 \\
\hline CPNF 4 & 21 & 70,0 & 9 & 30,0 & 0 & 0,0 \\
\hline CPNF 5 & 19 & 63,3 & 11 & 36,7 & 0 & 0,0 \\
\hline CPNF geral & 21 & 70,0 & 9 & 30,0 & 0 & 0,0 \\
\hline CPHRAC 1 & 11 & 36,7 & 19 & 63,3 & 0 & 0,0 \\
\hline CPHRAC 2 & 0 & 0,0 & 25 & 83,3 & 5 & 16,7 \\
\hline CPHRAC 3 & 10 & 33,3 & 17 & 56,7 & 3 & 10,0 \\
\hline CPHRAC 4 & 0 & 0,0 & 12 & 40,0 & 18 & 60,0 \\
\hline CPHRAC 5 & 4 & 13,3 & 24 & 80,0 & 2 & 6,7 \\
\hline CPHRAC geral & 2 & 6,7 & 24 & 80,0 & 4 & 13,3 \\
\hline ONF 1 & 19 & 63,3 & 11 & 36,7 & 0 & 0,0 \\
\hline ONF 2 & 17 & 56,7 & 13 & 43,3 & 0 & 0,0 \\
\hline ONF 3 & 7 & 23,3 & 20 & 66,7 & 3 & 10,0 \\
\hline ONF 4 & 21 & 70,0 & 9 & 30,0 & 0 & 0,0 \\
\hline ONF 5 & 25 & 83,3 & 5 & 16,7 & 0 & 0,0 \\
\hline ONF geral & 19 & 63,3 & 11 & 36,7 & 0 & 0,0 \\
\hline OHRAC 1 & 3 & 10,0 & 12 & 40,0 & 15 & 50,0 \\
\hline OHRAC 2 & 1 & 3,3 & 17 & 56,7 & 12 & 40,0 \\
\hline OHRAC 3 & 0 & 0,0 & 12 & 40,0 & 18 & 60,0 \\
\hline OHRAC 4 & 0 & 0,0 & 5 & 16,7 & 25 & 83,3 \\
\hline OHRAC 5 & 5 & 16,7 & 15 & 50,0 & 10 & 33,3 \\
\hline OHRAC - geral & 1 & 3,3 & 12 & 40,0 & 17 & 56,7 \\
\hline L 1 & 12 & 40,0 & 16 & 53,3 & 2 & 6,7 \\
\hline L 2 & 22 & 73,3 & 8 & 26,7 & 0 & 0,0 \\
\hline L 3 & 26 & 86,7 & 4 & 13,3 & 0 & 0,0 \\
\hline L 4 & 0 & 0,0 & 28 & 93,3 & 2 & 6,7 \\
\hline L 5 & 0 & 0,0 & 20 & 66,7 & 10 & 33,3 \\
\hline L geral & 12 & 40,0 & 17 & 56,7 & 1 & 3,3 \\
\hline
\end{tabular}

CPNF - Cirurgiões Plásticos não relacionados à área de fissura CPHRAC - Cirurgiões Plásticos do HRAC-USP

ONF - Ortodontistas não relacionados à área de fissura OHRAC - Ortodontistas do HRAC

L - Leigos com formação superior 


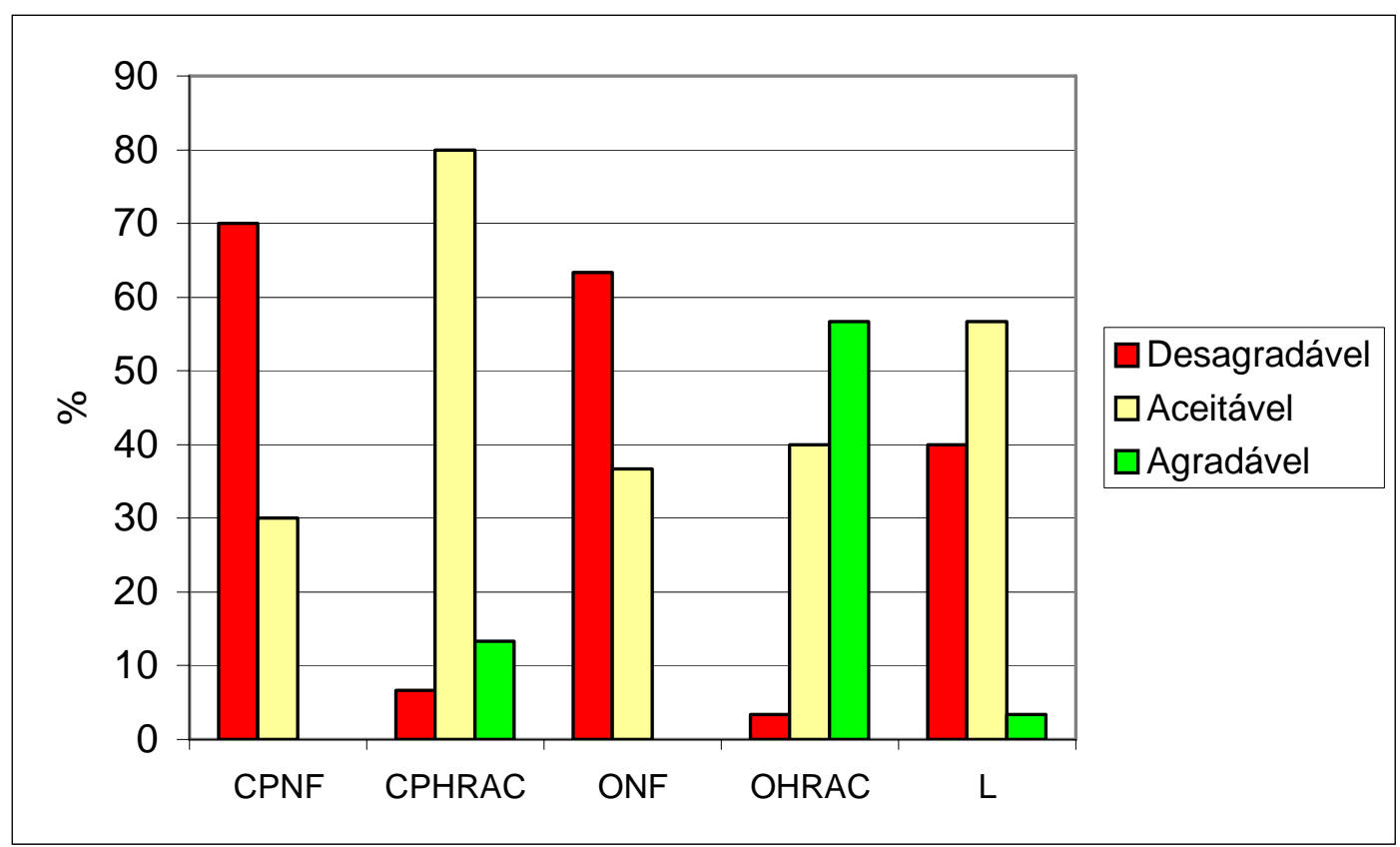

CPNF - Cirurgiões Plásticos não relacionados à área de fissura

CPHRAC - Cirurgiões Plásticos do HRAC-USP

ONF - Ortodontistas não relacionados à área de fissura

OHRAC - Ortodontistas do HRAC-USP

L - Leigos com formação superior

Figura 17 - Distribuição das classificações por categoria de examinador

Tabela 10 - Porcentagem de pacientes classificados como esteticamente desagradável, por categoria de examinador

\begin{tabular}{lc}
\hline Categoria & $\%$ \\
\hline OHRAC & 3,3 \\
CPHRAC & 6,7 \\
L & 40,0 \\
ONF & 63,3 \\
CPNF & 70,0 \\
\hline
\end{tabular}

CPNF - Cirurgiões Plásticos não relacionados à área de fissura CPHRAC - Cirurgiões Plásticos do HRAC-USP

ONF - Ortodontistas não relacionados à área de fissura OHRAC - Ortodontistas do HRAC-USP

L - Leigos com formação superior 


\subsection{Estruturas responsáveis pela classificação esteticamente desagradável.}

As informações obtidas pelos questionários, quanto aos escores 1, 2 e 3 foram interpretadas e relacionadas na tabela 11 e figura 18 como estruturas do perfil facial reconhecidas pelos avaliadores como responsáveis pela classificação em esteticamente desagradável.

Tabela 11 - Estruturas do perfil facial reconhecidas pelos examinadores como responsáveis pela classificação em esteticamente desagradável

\begin{tabular}{|c|c|c|c|c|c|c|}
\hline \multirow[b]{2}{*}{ Motivo } & \multicolumn{6}{|c|}{ Categoria de examinador } \\
\hline & CPNF & CPHRAC & ONF & OHRAC & $\mathrm{L}$ & $\begin{array}{l}\text { Total de } \\
\text { citações }\end{array}$ \\
\hline nariz & 74 & 10 & 39 & & 38 & 161 \\
\hline terço médio da face & 25 & 6 & 33 & 6 & & 70 \\
\hline lábio superior & 7 & 2 & 27 & & 12 & 48 \\
\hline retrognatismo & 12 & & 13 & & 1 & 26 \\
\hline mento/queixo & & & 2 & 2 & 21 & 25 \\
\hline ângulo naso labial & & 4 & 18 & & 2 & 24 \\
\hline lábio inferior & 1 & & 6 & 3 & 4 & 14 \\
\hline terço inferior da face & 2 & 2 & 7 & & & 11 \\
\hline desproporção maxilo/mandibular & 5 & 3 & & 3 & & 11 \\
\hline boca & & & 7 & & 2 & 9 \\
\hline face longa & 1 & & 3 & 1 & & 5 \\
\hline perfil reto & 1 & 1 & & & 3 & 5 \\
\hline perfil convexo & & & 3 & & & 3 \\
\hline testa & 2 & & & & 1 & 3 \\
\hline pele & & & & & 1 & 1 \\
\hline
\end{tabular}

CPNF - Cirurgiões Plásticos não relacionados à área de fissura

CPHRAC - Cirurgiões Plásticos do HRAC-USP

ONF - Ortodontistas não relacionados à área de fissura

OHRAC - Ortodontistas do HRAC-USP

L - Leigos com formação superior 


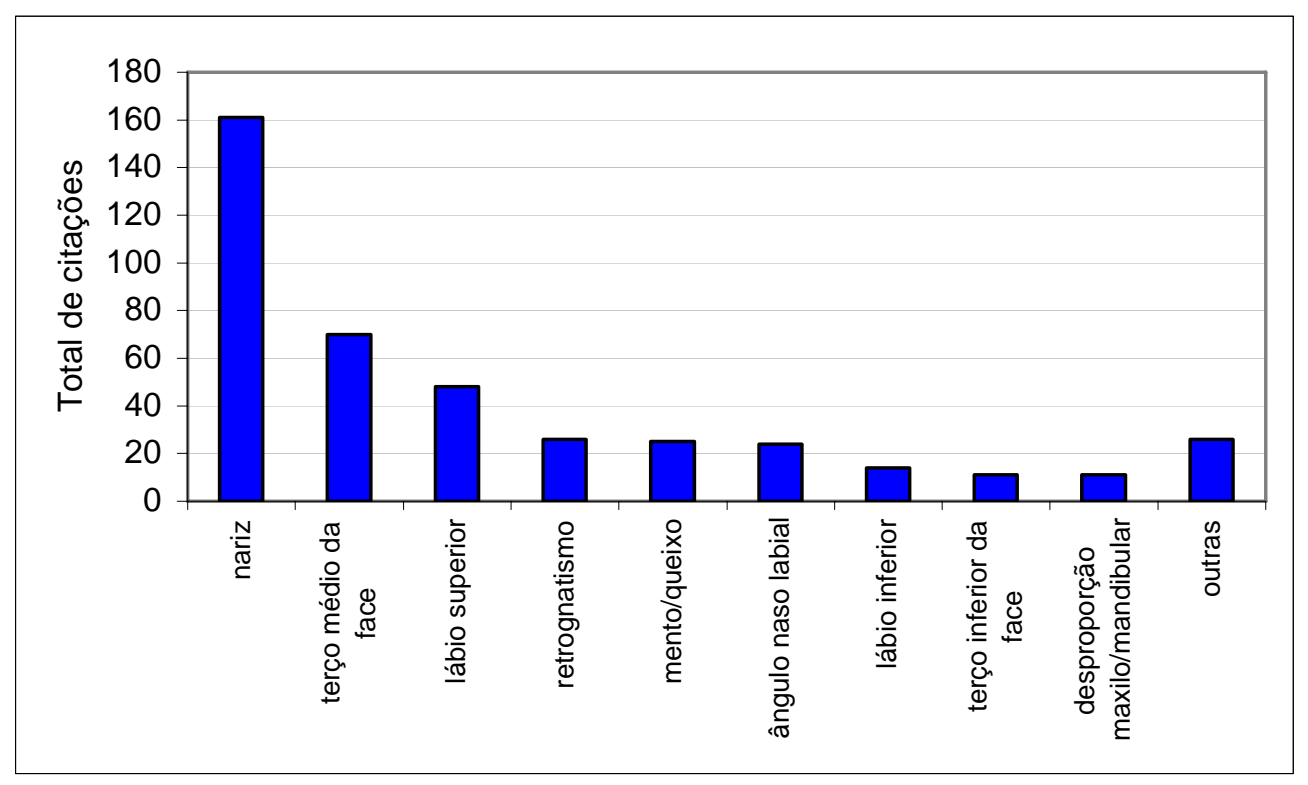

Figura 18 - Estruturas do perfil facial reconhecidas pelos examinadores como responsáveis pela classificação em esteticamente desagradável 
Discussão 


\section{DISCUSSÃO.}

\subsection{Considerações a respeito da metodologia.}

Várias metodologias de avaliação da estética, como slides (Phillips et al 1992), fotografias e apresentações ao vivo (Howells e Shaw 1985), fotografias modificadas (Shaw 1981), desenho do contorno do perfil (Okuyama e Martins 1997), e outros, foram descritas na literatura utilizando diferentes grupos de avaliadores, o que denota a possibilidade de julgamento da estética facial por diversos processos.

A proposta de se estudar estética em um trabalho científico, por si só já apresenta dificuldades, visto tratar-se de uma variável de difícil aferição e subjetiva do ponto de vista do examinador. Este foi um dos motivos para se utilizar diferentes categorias de examinadores com objetivo de se ter uma avaliação diversificada.

A decisão de se utilizar a metodologia de Reis (2001) neste, e em uma série de trabalhos desenvolvidos na Pós-Graduação do HRAC-USP, foi devido tratar-se de uma metodologia já testada, além da viabilidade de execução neste Hospital.

Este trabalho foi parte de um projeto maior que visa estabelecer e padronizar uma metodologia de avaliação estética dentro do HRAC-USP. A possibilidade de comparação dos presentes resultados com outros estudos que avaliam pacientes no estágio final da reabilitação, confere uma perspectiva de viabilidade de avaliação efetiva do protocolo de tratamento e dos resultados estéticos dos pacientes do HRAC-USP.

Durante a aplicação da metodologia de avaliação, as maiores dificuldades foram padronizar as especificações das tomadas fotográficas para uma maior qualidade da imagem. A caixa de luz confrontada com a luz do flash necessitou de vários testes até chegar na luminosidade adequada. O posicionamento dos pacientes, mantendo-os imóveis também consistiu uma dificuldade, principalmente dos mais jovens.

Outro fator a ser destacado foi a instrução aos examinadores. Eles não receberam informações sobre a amostra para conferir imparcialidade às respostas.

A metodologia mostrou-se viável e adequada para os objetivos propostos. 


\subsection{Considerações a respeito dos resultados.}

Após a avaliação das medianas dos escores atribuídos pelos examinadores, que foram relacionadas aos termos agradável, aceitável, e desagradável, foi verificado que os pacientes da amostra foram classificados nos 3 conceitos, dependendo do ponto de vista de cada grupo de examinadores (tabelas 1, 8, 9 e figuras 16 e 17 ).

O grupo de Ortodontistas do HRAC-USP (OHRAC) propiciou os melhores escores para os pacientes, sendo a mediana de 7 (aparência esteticamente agradável). Em segundo lugar, o grupo de Cirurgiões Plásticos do HRAC-USP (CPHRAC), que atribuiu 5 (aparência esteticamente aceitável). Em terceiro lugar o grupo de leigos com formação superior (L), que atribuiu 4 (aparência esteticamente aceitável). Por último, igualados em suas medianas, os grupos de Ortodontistas não relacionados à área de fissura (ONF) e Cirurgiões Plásticos não relacionados à área de fissura (CPNF), que designaram 3 (aparência esteticamente desagradável).

Deste modo, os pacientes da amostra foram considerados agradáveis para os Ortodontistas do HRAC-USP (OHRAC), aceitáveis para os Cirurgiões Plásticos do HRAC-USP (CPHRAC) e leigos com formação superior (L), e desagradáveis para os Ortodontistas e Cirurgiões Plásticos não relacionados à área de fissura (ONF e CPNF respectivamente).

Observou-se que o grupo OHRAC atribuiu escore mínimo de 3 e máximo de 8 . O grupo CPHRAC atribuiu escore mínimo de 3 e máximo de 7, assim como o grupo L. Já o grupo ONF concedeu escore mínimo de 2 e máximo de 5 . Finalmente o grupo CPNF que concedeu escore mínimo de 1 e máximo de 5 (tabela 8 e figura 16).

Representados na tabela 1 pela variação entre o $1^{\circ}$ e o $3^{\circ}$ quartil, os escores concentraram-se entre 6 e 7 para o grupo OHRAC, entre 4 e 6 para o grupo CPHRAC, entre 3 e 5 para o grupo L e entre 3 e 4 para os grupos ONF e CPNF.

Pelos resultados do teste de concordância verificou-se uma aceitável concordância intra-examinador e inter-examinador dentro de cada categoria de examinador (tabelas 3, 4 e 5). Isto demonstrou que existiu uma razoável concordância na categorização do menos agradável para o mais agradável entre os 30 pacientes, não indicando necessariamente que os valores atribuídos fossem parecidos entre os examinadores. 
Os escores foram diferentes provavelmente pela compreensão ou não da limitação à estética induzida pela doença.

Quando da comparação entre as categorias de examinadores também se verificou um Coeficiente de Concordância de médio a forte $(\mathrm{W}=0,65)$ mostrando que entre as 5 categorias existiu uma razoável concordância na categorização do menos agradável para o mais agradável entre os 30 pacientes.

Porém quando examinados os valores dos escores atribuídos verificou-se clara diferença entre as categorias, indo desde uma mediana de 3 para os ONF até 7 para os OHRAC (tabelas 7, 8 e figura 16). Estas diferenças foram comprovadas pelos testes estatísticos de Friedman e Student-Newman-Keuls que mostrou a seguinte ordem em valores atribuídos por categoria: OHRAC com mediana de 7, CPHRAC com mediana de 5, L com mediana de 4 e CPNF e ONF com mediana de 3, com significância estatística entre todas, exceto CPNF e ONF.

Pode-se sugerir que as diferenças advieram da interação do examinador com a estética e o conhecimento das características intrínsecas que o crescimento imprime na face do paciente com a deformidade, que difere do normal. Visto assim, há razão para os profissionais que não atuam com a fissura terem sido mais severos em suas notas, seguidos dos leigos que aceitaram a anormalidade com mais condescendência e por último os profissionais especialistas em fissura, que acostumados às suas limitações, viram uma agradabilidade na face de seus pacientes.

Os profissionais não relacionados à área da fissura possuem como comparativo os parâmetros de normalidade e por isso exigiram mais da estética dos pacientes da amostra. Já os profissionais experientes em fissura, sabendo da freqüência de resultados aquém da normalidade foram, desse modo, complacentes na atribuição de seus escores.

Os leigos, teoricamente desprovidos do conhecimento técnico específico, situaram-se na faixa intermediária dos escores atribuídos e provavelmente representam a avaliação mais próxima da sociedade onde o paciente está inserido.

A opinião do leigo é de extrema importância, pois, como Farkas e Kolar (1987) escreveram, o senso estético está relacionado a vários aspectos, tais como condições sócio-econômicas, fatores geográficos e conceitos culturais, sendo pela face que um indivíduo se apresenta à sociedade e é reconhecido por seus semelhantes. Logo, a estética que agrade os seus semelhantes assume grande importância na construção da auto-estima e na inter-relação pessoal. 
Os profissionais que atuam na reabilitação de fissuras possuem o conhecimento da complexidade do tratamento dessa deformidade, e da piora na estética da face com a idade, pois esta torna-se retrognática e longa (Capelozza Filho e Silva Filho 1992, Semb 1991, Vale 1991). A idade dos pacientes da amostra foi favorável para avaliação, pois antecedeu o crescimento puberal, e pôde-se examiná-los em uma fase provavelmente de melhor estética.

Entretanto, para os profissionais não relacionados à fissura, a grande maioria dos pacientes encontrava-se esteticamente desagradável ao passo que para os profissionais ligados ao HRAC-USP apenas uma minoria foi classificada nesta categoria.

Ficou claro que embora exista um razoável grau de concordância na ordenação da escala estética, as diferentes categorias atribuem valores mais altos ou baixos segundo seus conceitos próprios.

Isto dificulta o julgamento dos pacientes por um valor geral na escala visto que esta se mostrou dependente da categoria a que pertence o examinador. Portanto as comparações entre as categorias mostraram a variabilidade entre o ponto de vista do técnico, do técnico com experiência na área, e do leigo.

Do ponto de vista social a avaliação do leigo é mais importante para o paciente, pois eles representam a avaliação mais próxima da sociedade onde o paciente está inserido.

Do ponto de vista da reabilitação a avaliação dos profissionais não relacionados à área da fissura forneceram um parâmetro ótimo, a normalidade ou perfeição. Isso evidencia o quanto os resultados estão deficitários, o que é útil aos profissionais que militam na área.

Quanto às estruturas reconhecidas como responsáveis pelos escores baixos o nariz se destacou como a mais citada em todas categorias com exceção dos Ortodontistas do HRAC-USP (tabela 11 e figura 18).

O nariz é profundamente afetado pela fissura e pelas cirurgias reparadoras. Dentre os profissionais do HRAC-USP, os Cirurgiões Plásticos foram mais críticos pela sua própria experiência, provavelmente denotando a necessidade de novas intervenções cirúrgicas nesses pacientes. Sabe-se que a cirurgia plástica final de nariz é realizada na maturidade esquelética. Em contraponto, os Ortodontistas tiveram talvez o foco direcionado para a sua área de ação, que é a análise do perfil facial, separando-o em 
terços e observando suas proporções, para o diagnóstico e planejamento ortodôntico e da cirurgia ortognática, onde o nariz não tem a principal relevância.

Lo et al (2002), compararam a opinião de Cirurgiões Plásticos e leigos sobre a estética nasal de pacientes com fissura bilateral de lábio de 5 a 30 anos e encontraram similaridade de opinião nos dois grupos, com estética aceitável, mas aquém da ideal. Deve-se considerar porém, que devido à grande faixa etária da amostra, a maioria já havia sido submetida às reconstruções secundárias nasais.

A segunda estrutura mais citada como responsável pela classificação em esteticamente desagradável foi o terço médio da face, que na maioria dos casos encontrava-se retroposto. Nesse ponto os Ortodontistas não relacionados à área de fissura são concordantes aos Ortodontistas do HRAC-USP. Eles citaram o terço médio da face quase o mesmo número de vezes que o nariz (tabela 11).

A terceira estrutura reconhecida no aspecto de desagradabilidade foi o lábio superior. Os Ortodontistas não relacionados à área de fissura citaram fortemente essa região, seguidos dos leigos e dos Cirurgiões Plásticos não relacionados à área de fissura.

As estruturas mais reconhecidas como responsáveis pela classificação em esteticamente desagradável foram justamente as mais comprometidas pelo impacto da fissura e que guardam as marcas do prejuízo à estética que o crescimento e as intervenções reparadoras primárias impõem.

Esse achado denota a necessidade da busca de um protocolo de tratamento que se aproxime mais efetivamente dos apelos estéticos impostos pela sociedade e por isso, necessários para o bem estar e auto-estima dos indivíduos com fissura. Noar (1992) investigando o sucesso do tratamento de pacientes com fissura, observou que eles são emocional e socialmente afetados por suas fissuras e os Cirurgiões Plásticos, Fonoaudiólogos e Ortodontistas que trabalhavam em sua reabilitação não estavam satisfeitos como o resultado do tratamento, tanto a aparência facial como a fala.

Kapp (1979), comparando o autoconceito de 34 crianças com fissura com o mesmo número de crianças sem fissura notaram que as crianças com fissura demonstraram uma maior insatisfação com a aparência física em comparação às sem fissura.

Roberts-Harry et al (1992), que investigaram a classificação da estética de pacientes com e sem fissura, observaram que os pacientes com fissura foram 
considerados de pior estética facial que os sem fissura, na opinião unânime dos examinadores.

Aiello (2005)* fazendo uma análise do protocolo de tratamento com tração reversa da maxila em pacientes com fissura transforame incisivo unilateral observou resultados pouco expressivos. Com base nos dados desse trabalho, o autor recomenda muito cuidado na adoção desse procedimento.

Gaggl et al (1999) concluíram em seu estudo que, pelo prejuízo no crescimento da face média dos pacientes com fissura transforame incisivo bilateral, os melhores resultados só podem ser obtidos pela cirurgia ortognática.

Como foi constatado pelos resultados já discutidos nesse tópico, a estética dos pacientes da amostra foi positiva apenas para os Ortodontistas do HRAC-USP, profissionais acostumados às limitações do tratamento das fissuras e no resultado aquém da normalidade. Essa opinião é parcialmente compartilhada pelos Cirurgiões Plásticos do HRAC-USP, com experiência no tratamento e submetidos à mesma sensação de que o melhor possível com a terapia é aquém do normal.

O oposto é a opinião dos Ortodontistas e Cirurgiões Plásticos não relacionados à área de fissura, que mostram que, longe do normal (aceitável e agradável) está a estética da amostra estudada.

Mesmo admitindo que o agradável não seja meta para os pacientes com fissura reabilitados através de um protocolo consistente como o do HRAC-USP, o nível da agradabilidade conferido a eles por esses profissionais é preocupante.

Felizmente, a opinião leiga, a mais importante do ponto de vista social, expressou uma razoável aceitabilidade na classificação dos pacientes. Porém estes ainda estavam em fase de crescimento, e seriam submetidos a outros procedimentos terapêuticos incluindo cirurgias.

*dados ainda não publicados - dissertação a ser apresentada:

Aiello CA. Efeitos da tração reversa da maxila em pacientes com fissura transforame incisivo unilateral [dissertação]. Bauru: Hospital de Reabilitação de Anomalias Craniofaciais, Universidade de São Paulo; 2005. 
Segundo Semb (1991), que realizou um estudo longitudinal acompanhando o crescimento de pacientes com fissura transforame incisivo bilateral tratados em Oslo, Noruega, observou que a maxila, que é proeminente aos 5 anos, aos 7 tem a proeminência semelhante aos indivíduos sem fissura e aos 18 anos torna-se severamente retroposta. A mandíbula também diminui sua projeção com o crescimento. O crescimento torna-se cada vez mais vertical, principalmente do terço inferior da face. Esses dados são corroborados com os encontrados por Vale (1991), que também observou achatamento maior da base do crânio. As alterações encontradas em relação ao tecido mole foram evidenciadas pelo posicionamento mais posterior do nariz e lábio superior mais anterior do lábio inferior.

Desse modo, com o crescimento, a projeção nasal deve melhorar, mas a retroposição maxilar e a tendência vertical da face são fatores preocupantes no prognóstico de tratamento, devendo ser relevados no protocolo.

A pergunta a ser respondida através dessa linha de pesquisa do qual esse trabalho faz parte, é o que acontece com o crescimento e seus efeitos somados à terapia ao final do tratamento.

A resposta será importante para uma avaliação crítica do protocolo de tratamento do HRAC-USP para os pacientes com fissura transforame incisivo bilateral. 


$$
-
$$




\section{CONCLUSÕES.}

A partir dos resultados e considerações efetuadas, concluiu-se que:

- A estética dos pacientes com fissura transforame incisivo bilateral foi classificada da seguinte forma:

- aparência esteticamente agradável segundo o grupo de Ortodontistas do HRAC-USP (OHRAC), que atribuiu mediana de 7;

- aparência esteticamente aceitável segundo o grupo de Cirurgiões Plásticos do HRAC-USP (CPHRAC), com mediana de 5 e o grupo de leigos com formação superior (L), com mediana de 4 e;

- aparência esteticamente desagradável segundo os grupos de Ortodontistas não relacionados à área de fissura (ONF) e Cirurgiões Plásticos não relacionados à área de fissura (CPNF), com mediana de 3.

- Verificou-se um Coeficiente de Concordância de médio a forte (W=0,65) mostrando que entre as 5 categorias existiu uma razoável concordância na classificação do menos agradável para o mais agradável entre os 30 pacientes. Existiu diferença estatisticamente significante nos escores atribuídos entre todas categorias, exceto para os CPNF e ONF, sendo que os mais altos foram atribuídos pelos OHRAC (mediana de 7), depois pelos CPHRAC (mediana de 5), seguido pelos leigos (mediana de 4) e pelos ONF e CPNF, com mediana de 3 e sem diferença estatística.

- Dentre as estruturas da face que foram reconhecidas como responsáveis pela pior classificação (aparência esteticamente desagradável), o nariz se destacou como a mais citada em todas categorias com exceção dos Ortodontistas do HRAC-USP. A segunda estrutura mais citada foi o terço médio da face, que na maioria dos casos encontrava-se retroposto. A terceira estrutura foi o lábio superior. Os Ortodontistas não relacionados à área de fissura citaram fortemente essa região, seguidos dos leigos e dos Cirurgiões Plásticos não relacionados à área de fissura. 
Referências Bibliográficas 


\section{REFERÊNCIAS BIBLIOGRÁFICAS.}

Angle EH. Treatment of malocclusion of the teeth: Angle's system. 7th ed. Philadelphia: S. S. White; 1907.

Bass NM. The aesthetic analysis of the face. Eur J Orthod 1991; 13:343-50.

Bertier CE. Avaliação estética do lábio nos portadores de fissura pré-forame incisivo unilateral completa, submetidos a queiloplastia primária com a técnica de Spina [dissertação]. Botucatu: Faculdade de Medicina de Botucatu, Universidade Estadual Paulista “Júlio de Mesquita Filho”; 2001.

Broder HL, Smith FB, Strauss RP. Habilitation of patients with clefts: parent and child ratings of satisfaction with appearance and speech. Cleft Palate Craniofac J 1992; 29:262-7.

Capelozza Filho L, Silva Filho OG da. Abordagem interdisciplinar no tratamento das fissuras labiopalatinas. In: Mêlega JC, editor. Cirurgia Plástica fundamentos e arte: cirurgia reparadora da cabeça e pescoço. Rio de Janeiro: Medsi; 2002. p.59-88.

Capelozza Filho L, Silva Filho OG da. Fissuras lábio-palatais. In: Petrelli E, coord. Ortodontia para fonoaudiologia. Curitiba: Lovise; 1992. p.195-239.

Castilla E, Lopes-Camelo JS, Paz JE. Atlas geográfico de las malformaciones congénitas em Sudamérica. Rio de Janeiro: Fiocruz; 1995. p.58-9.

Cooke MS, Wei SHY. The reproducibility of natural head posture: a methodological study. Am J Orthod Dentofac Orthop 1988; 93:280-8. 
Czarnecki ST, Nanda RS, Currier GF. Perceptions of a balanced facial profile. Am J Orthod Dentofac Orthop 1993; 104:180-7.

Farkas LG, Kolar JC. Anthropometrics and art in the aesthetics of women's faces. Clin Plast Surg 1987; 14:599-616.

Freire-Maia BAV. Avaliação cefalométrica radiográfica da posição craniocervical de pacientes orientados em posição natural da cabeça pré e pós a expansão rápida da maxila [dissertação]. São Paulo: Faculdade de Odontologia, Universidade de São Paulo; 2003.

Gaggl A, Schultes G, Kärcher H. Aesthetic and functional outcome of surgical and orthodontic correction of bilateral clefts lip, palate, and alveolus. Cleft Palate Craniofac J 1999; 36:407-12.

Howells DJ, Shaw WC. The validity and reliability of ratings of dental and facial attractiveness for epidemiologic use. Am J Orthod 1985; 88:402-8.

Kapp K. Self concept of the cleft lip and or palate child. Cleft Palate J 1979; 16:171-6.

Morris W. An orthodontic view of dentofacial esthetics. Compendium 1994; 15:378-90.

Lo LJ, Wong FH, Mardini S, Chen YR, Noordhoff S. Assessment of bilateral cleft lip nose deformity: a comparison of results as judged by cleft surgeons and laypersons. Plast Reconstr Surg 2002; 110:733-41.

Nanda RS, Ghosh J. Harmonia entre os tecidos moles da face e o crescimento no tratamento ortodôntico. In: Sadowsky L et al, editors. Atualidades em ortodontia. São Paulo: Premier; 1997. p.65-78.

Noar JH. A questionnaire survey of attitudes and concerns of three professional groups involved in the cleft palate team. Cleft Palate Craniofac J 1992; 29:92-5. 
Okuyama CC, Martins DR. Preferência do perfil tegumentar, em jovens leucodermas, melanodermas e xantodermas de ambos os sexos, avaliados por ortodontistas, leigos e artistas Plásticos. Ortodontia 1997; 30:6-18.

Ozawa TO. Avaliação dos efeitos da queiloplastia e palatoplastia primária sobre o crescimento dos arcos dentários de crianças com fissura transforame incisivo unilateral aos $5 \sim 6$ anos de idade [tese]. Araraquara: Faculdade de Odontologia de Araraquara, Universidade Estadual Paulista “Júlio de Mesquita Filho” - UNESP; 2001.

Peck H, Peck S. A concept of facial esthetics. Angle Orthod 1970; 40:284-317.

Peng L, Cooke MS. Fifteen-year reproducibility of natural head posture: a longitudinal study. Am J Orthod Dentofac Orthop 1999; 116:82-5.

Phillips C, Tulloch C, Dann C. Rating of facial attractiveness. Community Dent Oral Epidemiol 1992; 20:214-20.

Reis SAB. Análise facial numérica e subjetiva do perfil e análise da relação oclusal sagital em brasileiros, adultos, leucodermas, não tratados ortodonticamente [dissertação]. São Bernardo do Campo: Universidade Metodista de São Paulo; 2001.

Rino Neto J, Freire-Maia BAV, Paiva JB. Método de registro da posição natural da cabeça para obtenção da radiografia cefalométrica lateral: considerações e importância do método no diagnóstico ortodôntico cirúrgico. Rev Dental Press Ortod Ortop Facial 2003; 8:61-71.

Roberts-Harry DP, Hathorn IS, Stephens CD. The ranking of facial attractiveness. Eur J Orthod 1992; 14:483-8.

Semb G. A study of facial growth in patients with bilateral cleft lip and palate treated by the Oslo CLP team. Cleft Palate Craniofac J 1991; 28:22-39. 
Shaw WC. The influence of children's dentofacial appearance on their social attractiveness as judged by peers and lay adults. Am J Orthod 1981; 79:399-415.

Shaw WC, Asher-McDade C, Mars M, Molsted K, Prahl-Andersen B, Semb G. A sixcenter international study of treatment outcome in patients with clefts of the lip and palate: Part 5. General discussion and conclusions. Cleft Palate J 1992; 29:413-8.

Siegel, S. Nonparametric statistics for the behavioral sciences. New York: McGrawHill; 1956.

Silva Filho OG da, Ferrari Júnior FM, Rocha DL, Souza Freitas JA. Classificação das fissuras lábio-palatais: breve histórico, considerações clínicas e sugestão de modificação. Rev Bras Cirurg 1992; 82:59-65.

Silva Filho OG da, Lauris RCMC, Capelozza Filho L, Semb G. Craniofacial morphology in adult patients with unoperated complete bilateral cleft lip and palate. Cleft Palate Craniofa J 1998; 35:111-9.

Spina V, Psillankis JM, Lapa FS, Ferreira, MC. Classificação das fissuras lábiopalatinas: sugestão de modificação. Rev Hosp Clin Fac Med S Paulo 1972; 27:5-6.

Vale DMV. Avaliação cefalomética de crescimento craniofacial e seu comportamento sob variáveis cirúrgicas, de jovens portadores de fissura transforame incisivo bilateral [tese]. Bauru: Faculdade de Odontologia de Bauru, Universidade de São Paulo; 1991.

Wuerpel EH. Ideals and idealism. Angle Orthod 1931; 1:14-31.

Zar, J.H. Biostatistical analysis. $3^{\text {rd }}$.ed. New Jersey: Prentice-Hall; 1996. 
Anexos 
Anexo 1. Ofício de aprovação pelo Comitê de Ética em Pesquisa. 
Anexo 2. Fotos da amostra.
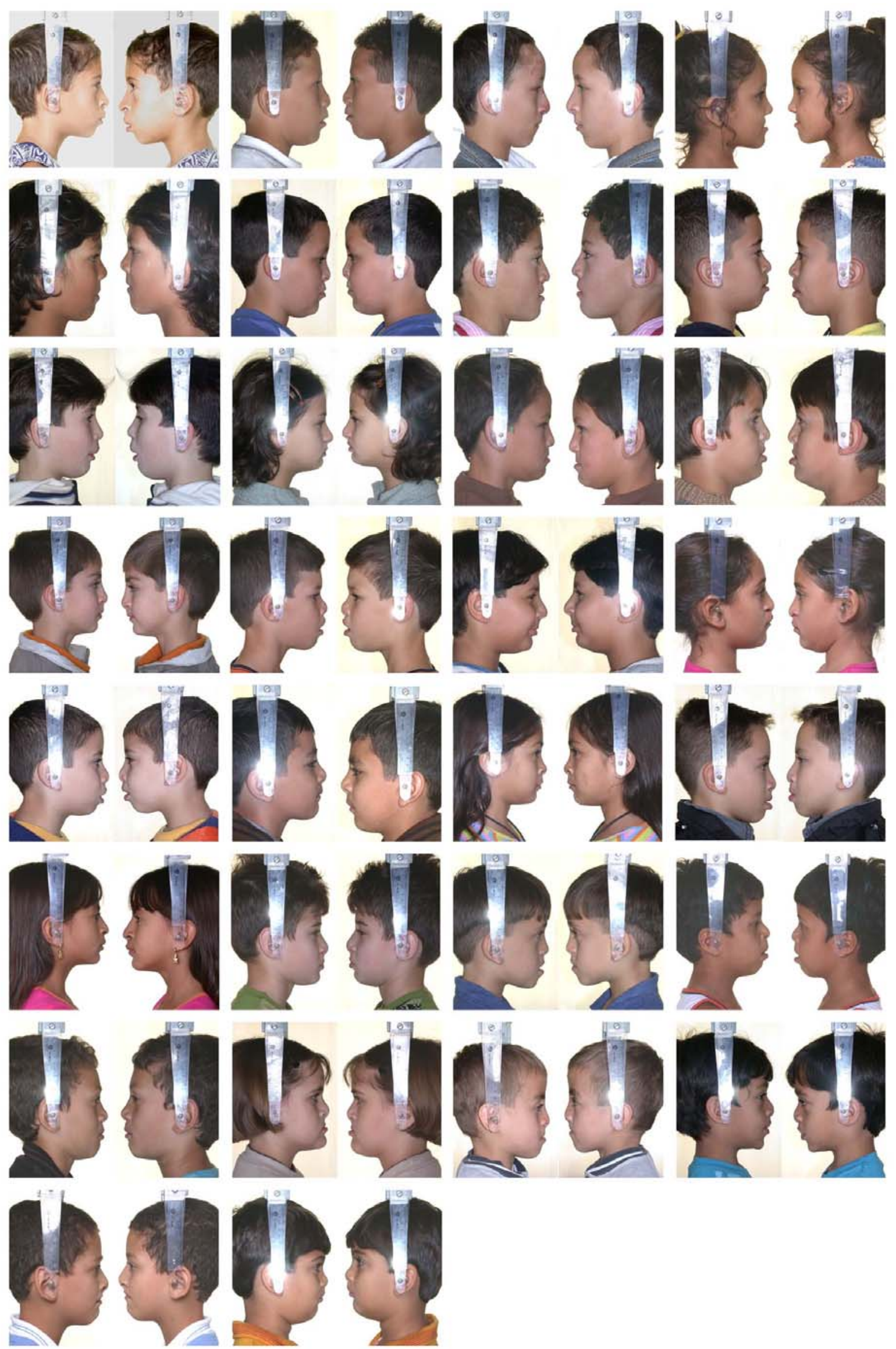
Anexo 3. Idades das cirurgias.

\begin{tabular}{|c|c|c|c|c|c|c|c|}
\hline \multirow{3}{*}{ Paciente } & \multicolumn{3}{|c|}{ Queiloplastia } & \multicolumn{3}{|c|}{ Palatoplastia } & \multirow{3}{*}{ Alongamento de columela } \\
\hline & \multirow{2}{*}{1 tempo } & \multicolumn{2}{|c|}{2 tempos } & \multirow{2}{*}{1 tempo } & \multicolumn{2}{|c|}{2 tempos } & \\
\hline & & 1o tempo & 2o tempo & & 10 tempo & 2o tempo & \\
\hline $\mathrm{P} 1$ & & $5 \mathrm{~m}$ & $9 \mathrm{~m}$ & & 1a4m & $2 \mathrm{a} 5 \mathrm{~m}$ & $7 \mathrm{a} 0 \mathrm{~m}$ \\
\hline P3 & $4 \mathrm{~m}$ & & & $1 \mathrm{a} 0 \mathrm{~m}$ & & & $5 \mathrm{a} 5 \mathrm{~m}$ \\
\hline P4 & $3 m$ & & & $1 \mathrm{a} 6 \mathrm{~m}$ & & & $5 \mathrm{a} 0 \mathrm{~m}$ \\
\hline P5 & $3 m$ & & & $1 \mathrm{a} 0 \mathrm{~m}$ & & & $4 \mathrm{a} 9 \mathrm{~m}$ \\
\hline P6 & $8 m$ & & & $1 \mathrm{a} 0 \mathrm{~m}$ & & & $7 \mathrm{a} 0 \mathrm{~m}$ \\
\hline P7 & $5 \mathrm{~m}$ & & & & $1 \mathrm{a} 1 \mathrm{~m}$ & $2 \mathrm{a} 4 \mathrm{~m}$ & $8 a 4 m$ \\
\hline P8 & $6 m$ & & & $1 \mathrm{a} 0 \mathrm{~m}$ & & & $5 \mathrm{a} 0 \mathrm{~m}$ \\
\hline P9 & $4 m$ & & & $1 \mathrm{a} 0 \mathrm{~m}$ & & & $5 \mathrm{a} 0 \mathrm{~m}$ \\
\hline $\mathrm{P} 10$ & $3 m$ & & & $1 \mathrm{a} 1 \mathrm{~m}$ & & & \\
\hline $\mathrm{P} 11$ & $3 m$ & & & $2 \mathrm{a} 8 \mathrm{~m}$ & & & \\
\hline P12 & $4 \mathrm{~m}$ & & & $1 \mathrm{a} 0 \mathrm{~m}$ & & & \\
\hline P13 & $3 m$ & & & $1 \mathrm{a} 0 \mathrm{~m}$ & & & $8 \mathrm{a} 3 \mathrm{~m}$ \\
\hline $\mathrm{P} 14$ & $3 m$ & & & $1 \mathrm{a} 0 \mathrm{~m}$ & & & $7 \mathrm{a} 0 \mathrm{~m}$ \\
\hline P15 & $3 m$ & & & $1 \mathrm{a} 0 \mathrm{~m}$ & & & $7 \mathrm{a} 11 \mathrm{~m}$ \\
\hline P17 & $5 \mathrm{~m}$ & & & $1 \mathrm{a} 9 \mathrm{~m}$ & & & \\
\hline P18 & $4 \mathrm{~m}$ & & & $1 \mathrm{a} 0 \mathrm{~m}$ & & & 5a10m \\
\hline P19 & $4 m$ & & & $1 \mathrm{a} 3 \mathrm{~m}$ & & & \\
\hline P20 & $3 m$ & & & 1a1m & & & \\
\hline P21 & $4 m$ & & & $1 \mathrm{a} 1 \mathrm{~m}$ & & & $6 a 1 m$ \\
\hline $\mathrm{P} 22$ & $3 m$ & & & $1 \mathrm{a} 2 \mathrm{~m}$ & & & $7 \mathrm{a} 5 \mathrm{~m}$ \\
\hline P23 & $3 m$ & & & $1 \mathrm{a} 3 \mathrm{~m}$ & & & \\
\hline $\mathrm{P} 24$ & $3 m$ & & & $3 a 9 m$ & & & \\
\hline P25 & $3 m$ & & & $1 \mathrm{a} 1 \mathrm{~m}$ & & & $5 \mathrm{a} 5 \mathrm{~m}$ \\
\hline P26 & $4 m$ & & & $1 \mathrm{a} 0 \mathrm{~m}$ & & & \\
\hline $\mathrm{P} 27$ & $4 m$ & & & $1 \mathrm{a} 0 \mathrm{~m}$ & & & \\
\hline P28 & $3 m$ & & & $1 \mathrm{a} 0 \mathrm{~m}$ & & & $6 a 3 m$ \\
\hline P29 & $4 \mathrm{~m}$ & & & $1 \mathrm{a} 7 \mathrm{~m}$ & & & \\
\hline P30 & $3 m$ & & & $1 \mathrm{a} 3 \mathrm{~m}$ & & & \\
\hline
\end{tabular}


Anexo 4. Ficha de avaliação clínica

\section{Dados Pessoais}

Data:

Nome: RG HRAC-USP

Endereço residencial:

Telefone res:

Telefone referência:

Celular:

Filiação:

Telefone comercial pai: mãe:

Idade: D.N.:

Ascendência:

pai: avô paterno: avó paterna: mãe: avô materno: avó materna:

\section{Queiloplastia:}

idade: técnica:

tempo cirúrgico:

( ) 1

( ) 2

cirurgias secundárias:

( ) sim

( ) não

em caso afirmativo, quais e época realizada:

\section{Palatoplastia:}

idade: técnica:

cirurgias secundárias: ( ) sim （） não

em caso afirmativo, quais e época realizada:

Alongamento de columela:

idade: técnica:

cirurgias secundárias: （ ） sim （ ） não

em caso afirmativo, quais e época realizada:

Documentação Inicial

Fotos: ( ) perfil direito ( ) perfil esquerdo

Data: 
Anexo 5. Termo de consentimento livre e esclarecido.

Eu, portador de RG $\mathrm{N}^{\mathrm{O}}$ residente à Rua (Av.) $\mathrm{N}^{\mathrm{O}}$ na cidade de Estado__, responsável pelo(a) menor matriculado no HRAC-USP com o $\mathrm{N}^{\mathrm{o}}$ autorizo sua participação na pesquisa de Título: “Avaliação da estética facial de pacientes com fissura transforame incisivo bilateral submetidos ao protocolo de cirurgias do HRAC-USP”, realizada por: Rita de Cássia

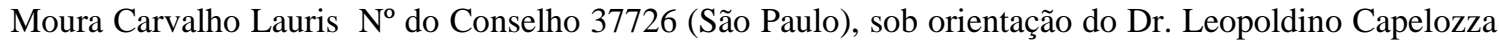
Filho, No do Conselho 10963 (São Paulo).

$\mathrm{Eu}$, portador de RG $\mathrm{N}^{\circ}$ declaro verdadeiras as afirmações relatadas. Declaro ainda estar ciente de que esta é uma seleção para pesquisa de análise facial desenvolvida pela cirurgiã-dentista Rita de Cássia Moura Carvalho Lauris, aluna do curso de Mestrado em Fissuras Orofaciais do Hospital de Reabilitação de Anomalias Craniofaciais - USP. Aceito ter a face fotografada de frente e perfil com a cabeça posicionada no cefalostato. Concedo ao HRAC-USP totais direitos quanto ao uso do material coletado com finalidade de ensino e divulgação, dentro das normas vigentes, tais como a publicação em jornais e/ou revistas científicas do país e do exterior.

Estou ciente também de que minha participação é voluntária e dela posso desistir a qualquer momento, sem explicar os motivos e sem comprometer meu tratamento no HRAC-USP.

Bauru, 1

Assinatura do Responsável

Nome do Pesquisador Responsável: Rita de Cássia Moura Carvalho Lauris

Endereço Institucional: Rua Silvio Marchione, 3-20

Cidade: Bauru Estado: SP CEP: 17043-900

Telefone: 3235-8146 
Anexo 6. Carta de informação aos examinadores.

$\operatorname{Caro}(\mathrm{a}) \operatorname{Sr}(\mathrm{a})$

Esta é uma pesquisa de avaliação da estética da face. Agradecemos antecipadamente sua disponibilidade em nos auxiliar neste trabalho.

Apresentaremos um álbum contendo fotografias faciais de indivíduos de ambos os sexos, sendo duas fotos por indivíduo, perfil direito e perfil esquerdo. Solicitaremos que, no máximo em 30 segundos, sejam dadas notas de 1 a 9 considerando a aparência estética do indivíduo fotografado (uma única nota por sujeito).

Solicitamos que seja utilizado o seguinte critério de avaliação:

Notas:

1, 2 ou 3: aparência esteticamente desagradável

4, 5 ou 6: aparência esteticamente aceitável

7, 8 ou 9: aparência esteticamente agradável

Caso as notas sejam 1,2 ou 3, favor descrever o motivo pelo qual você considerou o indivíduo esteticamente desagradável.

Antecipadamente gratos,

Rita de Cássia Moura Carvalho Lauris

Pesquisadora

Prof. Dr. Leopoldino Capelozza Filho

Orientador 
Anexo 7. Ficha de classificação estética.

\begin{tabular}{|c|c|c|}
\hline Examinador: & & \\
\hline Indivíduo & Nota & Se a nota foi 1,2 ou 3 , explique porquê \\
\hline 1 & & \\
\hline 2 & & \\
\hline 3 & & \\
\hline 4 & & \\
\hline 5 & & \\
\hline 6 & & \\
\hline 7 & & \\
\hline 8 & & \\
\hline 9 & & \\
\hline 10 & & \\
\hline 11 & & \\
\hline 12 & & \\
\hline 13 & & \\
\hline 14 & & \\
\hline 15 & & \\
\hline 16 & & \\
\hline 17 & & \\
\hline 18 & & \\
\hline 19 & & \\
\hline 20 & & \\
\hline 21 & & \\
\hline 22 & & \\
\hline 23 & & \\
\hline 24 & & \\
\hline 25 & & \\
\hline 26 & & \\
\hline 27 & & \\
\hline 28 & & \\
\hline 29 & & \\
\hline 30 & & \\
\hline
\end{tabular}

Notas:

1, 2 ou 3: aparência esteticamente desagradável

4, 5 ou 6: aparência esteticamente aceitável

7, 8 ou 9: aparência esteticamente agradável 
Anexo 8. Escores individuais atribuídos pelos 5 grupos de examinadores na $1^{\mathrm{a}}$ avaliação.

\begin{tabular}{|c|c|c|c|c|c|c|c|c|c|c|c|c|c|c|c|c|c|c|c|c|c|c|c|c|c|c|c|}
\hline \multirow{3}{*}{ Paciente } & \multirow{3}{*}{ Gênero } & \multirow{3}{*}{ Idade } & \multicolumn{25}{|c|}{ Examinadores } \\
\hline & & & \multicolumn{5}{|c|}{$\begin{array}{l}\text { Cir. Plásticos não } \\
\text { relacionados à área de } \\
\text { fissura }\end{array}$} & \multicolumn{5}{|c|}{ Cir. Plásticos HRAC-USP } & \multicolumn{5}{|c|}{$\begin{array}{c}\text { Ortodontistas não } \\
\text { relacionados à área de } \\
\text { fissura }\end{array}$} & \multicolumn{5}{|c|}{ Ortodontistas HRAC-USP } & \multicolumn{5}{|c|}{$\begin{array}{l}\text { Leigos com formação } \\
\text { superior }\end{array}$} \\
\hline & & & E1 & E2 & E3 & E4 & E5 & E1 & E2 & E3 & E4 & E5 & E1 & E2 & E3 & E4 & E5 & E1 & E2 & E3 & E4 & E5 & E1 & E2 & E3 & E4 & E5 \\
\hline P1 & $\mathrm{m}$ & $10 \mathrm{a} 4 \mathrm{~m}$ & 5 & 3 & 3 & 4 & 4 & 6 & 6 & 6 & 8 & 5 & 2 & 3 & 5 & 3 & 2 & 7 & 7 & 8 & 8 & 6 & 3 & 3 & 3 & 6 & 5 \\
\hline P2 & $\mathrm{m}$ & 9a1m & 3 & 1 & 3 & 3 & 3 & 3 & 6 & 4 & 7 & 5 & 1 & 2 & 3 & 2 & 2 & 7 & 6 & 7 & 8 & 5 & 3 & 3 & 3 & 4 & 6 \\
\hline P3 & $\mathrm{m}$ & $9 a 3 m$ & 2 & 1 & 3 & 2 & 3 & 5 & 5 & 3 & 7 & 4 & 1 & 4 & 4 & 3 & 1 & 5 & 5 & 6 & 7 & 3 & 3 & 3 & 3 & 4 & 6 \\
\hline P4 & $f$ & $8 a 11 m$ & 3 & 1 & 3 & 3 & 3 & 4 & 4 & 3 & 4 & 1 & 1 & 3 & 2 & 2 & 1 & 1 & 3 & 4 & 6 & 1 & 3 & 3 & 3 & 4 & 4 \\
\hline P5 & $\mathrm{m}$ & $8 a 11 m$ & 3 & 2 & 2 & 3 & 3 & 5 & 7 & 3 & 7 & 6 & 4 & 5 & 6 & 4 & 1 & 8 & 6 & 6 & 7 & 7 & 5 & 5 & 3 & 5 & 4 \\
\hline P6 & $\mathrm{m}$ & 9a1m & 3 & 1 & 3 & 1 & 3 & 4 & 6 & 5 & 6 & 5 & 3 & 4 & 3 & 4 & 1 & 8 & 7 & 8 & 8 & 6 & 3 & 3 & 3 & 4 & 4 \\
\hline P7 & $\mathrm{m}$ & 9a1m & 4 & 3 & 1 & 2 & 3 & 5 & 6 & 7 & 6 & 6 & 2 & 4 & 5 & 3 & 1 & 6 & 6 & 7 & 7 & 6 & 4 & 3 & 4 & 4 & 6 \\
\hline P8 & $\mathrm{m}$ & $8 a 9 m$ & 4 & 3 & 3 & 4 & 4 & 5 & 6 & 3 & 6 & 6 & 3 & 3 & 4 & 3 & 2 & 7 & 7 & 7 & 7 & 6 & 3 & 3 & 3 & 5 & 5 \\
\hline P9 & $\mathrm{m}$ & $8 a 7 m$ & 3 & 1 & 2 & 3 & 3 & 6 & 5 & 5 & 7 & 5 & 1 & 2 & 2 & 2 & 1 & 6 & 6 & 7 & 7 & 6 & 3 & 3 & 3 & 5 & 7 \\
\hline P10 & $f$ & $8 a 5 m$ & 3 & 4 & 4 & 4 & 5 & 6 & 7 & 7 & 8 & 5 & 4 & 6 & 7 & 5 & 3 & 6 & 8 & 8 & 7 & 8 & 5 & 4 & 3 & 6 & 9 \\
\hline P11 & $\mathrm{m}$ & $8 a 6 m$ & 3 & 3 & 4 & 3 & 3 & 4 & 4 & 4 & 6 & 4 & 3 & 3 & 4 & 3 & 2 & 4 & 5 & 6 & 6 & 3 & 5 & 3 & 3 & 5 & 6 \\
\hline P12 & $\mathrm{m}$ & 8a1m & 3 & 2 & 4 & 4 & 2 & 4 & 4 & 4 & 4 & 3 & 2 & 2 & 3 & 3 & 2 & 4 & 5 & 4 & 5 & 4 & 5 & 3 & 3 & 4 & 6 \\
\hline P13 & $f$ & $8 a 3 m$ & 4 & 3 & 2 & 1 & 4 & 3 & 4 & 4 & 7 & 4 & 2 & 3 & 4 & 3 & 1 & 9 & 6 & 8 & 7 & 5 & 4 & 3 & 3 & 6 & 6 \\
\hline P14 & $\mathrm{m}$ & $8 \mathrm{a} 0 \mathrm{~m}$ & 5 & 5 & 4 & 4 & 4 & 6 & 6 & 3 & 8 & 5 & 4 & 4 & 5 & 2 & 2 & 7 & 7 & 7 & 7 & 7 & 4 & 4 & 3 & 5 & 7 \\
\hline P15 & $\mathrm{m}$ & $7 a 4 m$ & 3 & 3 & 3 & 2 & 3 & 5 & 5 & 5 & 8 & 5 & 3 & 3 & 5 & 3 & 2 & 5 & 7 & 8 & 8 & 5 & 4 & 4 & 3 & 6 & 7 \\
\hline $\mathrm{P} 16$ & $\mathrm{~m}$ & $7 a 4 m$ & 3 & 2 & 3 & 2 & 3 & 3 & 4 & 3 & 8 & 5 & 4 & 4 & 4 & 3 & 2 & 7 & 7 & 5 & 7 & 7 & 3 & 3 & 3 & 4 & 7 \\
\hline P17 & $\mathrm{m}$ & $7 a 4 m$ & 4 & 3 & 3 & 3 & 4 & 3 & 5 & 5 & 8 & 5 & 4 & 3 & 4 & 3 & 2 & 4 & 6 & 6 & 7 & 5 & 3 & 3 & 3 & 4 & 6 \\
\hline P18 & $\mathrm{m}$ & $7 a 8 m$ & 5 & 5 & 4 & 4 & 4 & 5 & 8 & 4 & 9 & 7 & 4 & 4 & 7 & 4 & 4 & 9 & 7 & 8 & 8 & 8 & 6 & 4 & 4 & 5 & 8 \\
\hline P19 & $f$ & $7 a 8 m$ & 5 & 5 & 4 & 4 & 5 & 5 & 8 & 7 & 8 & 5 & 4 & 4 & 7 & 6 & 4 & 9 & 8 & 8 & 8 & 8 & 7 & 5 & 4 & 7 & 9 \\
\hline P20 & $\mathrm{m}$ & 7a6m & 4 & 3 & 3 & 3 & 3 & 3 & 6 & 6 & 6 & 4 & 3 & 3 & 4 & 3 & 2 & 6 & 6 & 6 & 7 & 5 & 5 & 3 & 3 & 6 & 8 \\
\hline P21 & $f$ & $7 a 6 m$ & 4 & 5 & 4 & 3 & 6 & 6 & 6 & 6 & 7 & 6 & 4 & 4 & 4 & 4 & 3 & 7 & 8 & 8 & 8 & 9 & 5 & 3 & 3 & 6 & 8 \\
\hline P22 & $\mathrm{m}$ & $7 \mathrm{a} 4 \mathrm{~m}$ & 3 & 4 & 3 & 3 & 3 & 3 & 5 & 5 & 8 & 5 & 4 & 5 & 5 & 4 & 4 & 9 & 7 & 7 & 8 & 8 & 4 & 3 & 3 & 5 & 7 \\
\hline P23 & $\mathrm{m}$ & $7 a 2 m$ & 3 & 6 & 3 & 3 & 3 & 5 & 6 & 4 & 7 & 6 & 2 & 3 & 4 & 3 & 1 & 5 & 5 & 6 & 7 & 6 & 4 & 5 & 3 & 4 & 6 \\
\hline P24 & $\mathrm{m}$ & 7a1m & 3 & 2 & 2 & 2 & 2 & 5 & 6 & 3 & 7 & 5 & 2 & 3 & 4 & 2 & 2 & 6 & 5 & 6 & 7 & 4 & 4 & 3 & 3 & 5 & 6 \\
\hline P25 & $\mathrm{m}$ & $7 \mathrm{a} 1 \mathrm{~m}$ & 4 & 6 & 4 & 4 & 4 & 6 & 8 & 5 & 8 & 7 & 6 & 4 & 4 & 4 & 4 & 9 & 5 & 8 & 8 & 7 & 7 & 6 & 4 & 8 & 6 \\
\hline P26 & $f$ & 6a11m & 3 & 3 & 1 & 2 & 3 & 3 & 4 & 3 & 4 & 3 & 1 & 2 & 2 & 2 & 2 & 2 & 4 & 4 & 6 & 2 & 3 & 3 & 3 & 4 & 5 \\
\hline P27 & $m$ & $7 \mathrm{a} 0 \mathrm{~m}$ & 2 & 1 & 1 & 2 & 1 & 3 & 4 & 3 & 5 & 3 & 1 & 2 & 2 & 3 & 2 & 3 & 4 & 4 & 6 & 3 & 3 & 3 & 3 & 4 & 5 \\
\hline P28 & $\mathrm{m}$ & $6 a 2 m$ & 3 & 2 & 3 & 3 & 3 & 3 & 4 & 4 & 6 & 5 & 4 & 3 & 4 & 4 & 3 & 7 & 7 & 7 & 7 & 7 & 4 & 3 & 3 & 5 & 6 \\
\hline P29 & $\mathrm{m}$ & $5 a 9 m$ & 3 & 3 & 4 & 4 & 4 & 3 & 4 & 4 & 6 & 4 & 3 & 4 & 4 & 3 & 4 & 8 & 6 & 7 & 8 & 6 & 3 & 3 & 3 & 4 & 6 \\
\hline P30 & $\mathrm{m}$ & $5 \mathrm{a} 8 \mathrm{~m}$ & 3 & 3 & 2 & 2 & 3 & 3 & 6 & 3 & 6 & 4 & 3 & 3 & 5 & 2 & 2 & 6 & 5 & 7 & 8 & 6 & 4 & 3 & 3 & 5 & 5 \\
\hline
\end{tabular}


Anexo 9. Escores individuais atribuídos pelos 5 grupos de examinadores na $2^{\text {a }}$ avaliação.

\begin{tabular}{|c|c|c|c|c|c|c|c|c|c|c|c|c|c|c|c|c|c|c|c|c|c|c|c|c|c|c|c|}
\hline \multirow{3}{*}{ Paciente } & \multirow{3}{*}{ Gênero } & \multirow{3}{*}{ Idade } & \multicolumn{25}{|c|}{ Examinadores } \\
\hline & & & \multicolumn{5}{|c|}{$\begin{array}{l}\text { Cir. Plásticos não } \\
\text { relacionados à área de } \\
\text { fissura }\end{array}$} & \multicolumn{5}{|c|}{ Cir. Plásticos HRAC } & \multicolumn{5}{|c|}{$\begin{array}{c}\text { Ortodontistas não } \\
\text { relacionados à área de } \\
\text { fissura }\end{array}$} & \multicolumn{5}{|c|}{ Ortodontistas HRAC } & \multicolumn{5}{|c|}{$\begin{array}{l}\text { Leigos com formação } \\
\text { superior }\end{array}$} \\
\hline & & & E1 & E2 & E3 & E4 & E5 & E1 & E2 & E3 & E4 & E5 & E1 & E2 & E3 & E4 & E5 & E1 & E2 & E3 & E4 & E5 & E1 & E2 & E3 & E4 & E5 \\
\hline P1 & $\mathrm{m}$ & $10 \mathrm{a} 4 \mathrm{~m}$ & 3 & 3 & 4 & 3 & 3 & 6 & 6 & 8 & 7 & 8 & 5 & 4 & 5 & 3 & 3 & 6 & 7 & 7 & 7 & 5 & 5 & 3 & 3 & 6 & 6 \\
\hline P2 & $\mathrm{m}$ & 9a1m & 2 & 2 & 2 & 3 & 3 & 3 & 5 & 6 & 6 & 7 & 4 & 3 & 4 & 1 & 4 & 6 & 6 & 7 & 8 & 5 & 3 & 3 & 3 & 5 & 6 \\
\hline P3 & $\mathrm{m}$ & $9 a 3 m$ & 3 & 1 & 3 & 2 & 2 & 4 & 4 & 6 & 6 & 4 & 4 & 3 & 3 & 3 & 1 & 4 & 5 & 7 & 6 & 3 & 3 & 3 & 3 & 5 & 5 \\
\hline P4 & $f$ & $8 a 11 m$ & 3 & 1 & 2 & 3 & 3 & 3 & 4 & 4 & 4 & 2 & 3 & 3 & 3 & 2 & 1 & 2 & 4 & 4 & 4 & 1 & 4 & 4 & 3 & 6 & 4 \\
\hline P5 & $\mathrm{m}$ & $8 a 11 m$ & 4 & 3 & 4 & 3 & 3 & 5 & 6 & 5 & 5 & 8 & 4 & 4 & 5 & 4 & 4 & 8 & 4 & 8 & 6 & 7 & 5 & 5 & 4 & 6 & 5 \\
\hline P6 & $\mathrm{m}$ & 9a1m & 3 & 2 & 2 & 3 & 3 & 5 & 5 & 5 & 5 & 6 & 3 & 3 & 4 & 3 & 3 & 6 & 5 & 7 & 8 & 4 & 3 & 3 & 3 & 5 & 5 \\
\hline P7 & $\mathrm{m}$ & 9a1m & 3 & 2 & 3 & 3 & 3 & 6 & 6 & 7 & 6 & 6 & 3 & 3 & 5 & 3 & 3 & 6 & 5 & 7 & 7 & 4 & 4 & 4 & 3 & 5 & 5 \\
\hline P8 & $\mathrm{m}$ & $8 a 9 m$ & 4 & 2 & 1 & 3 & 3 & 6 & 6 & 6 & 6 & 6 & 4 & 3 & 5 & 3 & 4 & 7 & 6 & 7 & 8 & 4 & 4 & 3 & 4 & 5 & 5 \\
\hline P9 & $\mathrm{m}$ & $8 a 7 m$ & 3 & 2 & 1 & 3 & 3 & 6 & 6 & 5 & 6 & 5 & 3 & 2 & 3 & 1 & 3 & 6 & 7 & 6 & 7 & 5 & 3 & 3 & 3 & 5 & 6 \\
\hline P10 & $f$ & $8 \mathrm{a} 5 \mathrm{~m}$ & 3 & 3 & 4 & 3 & 5 & 6 & 7 & 8 & 7 & 5 & 6 & 5 & 5 & 4 & 4 & 5 & 8 & 8 & 7 & 7 & 5 & 4 & 4 & 6 & 7 \\
\hline P11 & $\mathrm{m}$ & $8 a 6 m$ & 3 & 3 & 3 & 2 & 2 & 4 & 6 & 6 & 5 & 4 & 4 & 3 & 4 & 3 & 3 & 4 & 5 & 6 & 6 & 3 & 5 & 5 & 3 & 6 & 6 \\
\hline P12 & $\mathrm{m}$ & $8 a 1 m$ & 2 & 3 & 2 & 2 & 2 & 3 & 6 & 6 & 6 & 4 & 3 & 3 & 4 & 3 & 3 & 6 & 4 & 5 & 5 & 2 & 4 & 4 & 3 & 6 & 6 \\
\hline P13 & $f$ & $8 a 3 m$ & 3 & 3 & 1 & 2 & 2 & 3 & 6 & 4 & 6 & 3 & 4 & 3 & 4 & 3 & 2 & 7 & 5 & 8 & 7 & 3 & 4 & 3 & 3 & 5 & 6 \\
\hline P14 & $\mathrm{m}$ & $8 \mathrm{a} 0 \mathrm{~m}$ & 4 & 3 & 3 & 2 & 4 & 6 & 8 & 6 & 7 & 6 & 5 & 3 & 5 & 2 & 4 & 7 & 5 & 8 & 7 & 5 & 4 & 4 & 4 & 7 & 6 \\
\hline P15 & $\mathrm{m}$ & $7 a 4 m$ & 3 & 3 & 1 & 3 & 4 & 3 & 6 & 5 & 6 & 7 & 4 & 2 & 5 & 3 & 2 & 6 & 6 & 8 & 8 & 4 & 4 & 3 & 4 & 6 & 7 \\
\hline P16 & $\mathrm{m}$ & $7 \mathrm{a} 4 \mathrm{~m}$ & 3 & 2 & 3 & 2 & 4 & 3 & 6 & 4 & 6 & 7 & 4 & 4 & 4 & 3 & 3 & 5 & 7 & 8 & 7 & 6 & 5 & 3 & 3 & 5 & 6 \\
\hline P17 & $\mathrm{m}$ & $7 \mathrm{a} 4 \mathrm{~m}$ & 3 & 2 & 4 & 3 & 3 & 3 & 6 & 4 & 7 & 7 & 4 & 3 & 4 & 2 & 4 & 6 & 7 & 7 & 6 & 4 & 4 & 3 & 3 & 6 & 6 \\
\hline P18 & $\mathrm{m}$ & $7 \mathrm{a} 8 \mathrm{~m}$ & 3 & 3 & 4 & 3 & 5 & 6 & 7 & 6 & 7 & 9 & 6 & 4 & 5 & 4 & 4 & 8 & 7 & 8 & 7 & 7 & 6 & 5 & 4 & 7 & 5 \\
\hline P19 & $f$ & $7 a 8 m$ & 4 & 3 & 5 & 3 & 5 & 6 & 7 & 8 & 6 & 9 & 7 & 5 & 6 & 5 & 4 & 9 & 8 & 8 & 8 & 6 & 5 & 7 & 4 & 6 & 7 \\
\hline P20 & $\mathrm{m}$ & $7 a 6 m$ & 3 & 3 & 3 & 2 & 3 & 4 & 6 & 5 & 7 & 6 & 4 & 3 & 5 & 3 & 3 & 6 & 6 & 7 & 7 & 4 & 4 & 3 & 3 & 5 & 7 \\
\hline P21 & $f$ & $7 \mathrm{a} 6 \mathrm{~m}$ & 4 & 4 & 3 & 3 & 5 & 6 & 6 & 7 & 7 & 8 & 5 & 4 & 4 & 4 & 3 & 7 & 8 & 9 & 8 & 7 & 6 & 4 & 3 & 6 & 7 \\
\hline P22 & $\mathrm{m}$ & $7 a 4 m$ & 3 & 3 & 3 & 3 & 4 & 3 & 5 & 5 & 7 & 6 & 5 & 4 & 4 & 4 & 4 & 8 & 6 & 8 & 8 & 5 & 4 & 3 & 3 & 7 & 8 \\
\hline P23 & $\mathrm{m}$ & $7 a 2 m$ & 2 & 3 & 4 & 3 & 3 & 5 & 4 & 7 & 6 & 5 & 4 & 3 & 4 & 3 & 3 & 4 & 6 & 7 & 7 & 5 & 4 & 3 & 3 & 5 & 7 \\
\hline P24 & $\mathrm{m}$ & 7a1m & 2 & 1 & 2 & 2 & 2 & 4 & 4 & 4 & 7 & 5 & 3 & 2 & 2 & 2 & 2 & 6 & 5 & 6 & 7 & 4 & 4 & 3 & 3 & 5 & 6 \\
\hline P25 & $\mathrm{m}$ & 7a1m & 4 & 3 & 3 & 3 & 5 & 6 & 7 & 6 & 5 & 7 & 5 & 4 & 6 & 4 & 4 & 8 & 7 & 8 & 7 & 6 & 5 & 6 & 4 & 6 & 7 \\
\hline P26 & $f$ & $6 a 11 m$ & 3 & 3 & 1 & 2 & 2 & 3 & 4 & 3 & 5 & 3 & 3 & 2 & 3 & 2 & 2 & 3 & 5 & 5 & 5 & 2 & 3 & 3 & 3 & 5 & 5 \\
\hline P27 & $\mathrm{m}$ & $7 \mathrm{a} 0 \mathrm{~m}$ & 3 & 1 & 1 & 2 & 2 & 3 & 4 & 3 & 6 & 3 & 3 & 2 & 3 & 2 & 2 & 3 & 5 & 5 & 5 & 2 & 4 & 3 & 3 & 5 & 5 \\
\hline P28 & $\mathrm{m}$ & $6 a 2 m$ & 3 & 2 & 1 & 3 & 4 & 3 & 4 & 5 & 5 & 6 & 5 & 3 & 4 & 3 & 4 & 4 & 4 & 8 & 7 & 4 & 4 & 3 & 3 & 6 & 5 \\
\hline P29 & $\mathrm{m}$ & $5 a 9 m$ & 3 & 2 & 3 & 3 & 4 & 3 & 6 & 4 & 5 & 4 & 3 & 3 & 4 & 3 & 4 & 8 & 7 & 7 & 7 & 3 & 4 & 3 & 3 & 5 & 5 \\
\hline P30 & $\mathrm{m}$ & $5 \mathrm{a} 8 \mathrm{~m}$ & 3 & 2 & 1 & 3 & 3 & 3 & 6 & 4 & 5 & 3 & 3 & 3 & 4 & 3 & 4 & 6 & 6 & 7 & 6 & 4 & 4 & 3 & 3 & 6 & 4 \\
\hline
\end{tabular}

